$$
\begin{aligned}
& \text { " }
\end{aligned}
$$

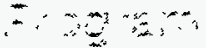

$$
\begin{aligned}
& \text { 4rama } \\
& \text { in } 20 \text { ) } \\
& 20 \text { 年 }
\end{aligned}
$$

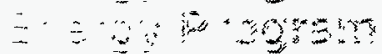

Fossil Energy Program Fossil Energy Program Fossil Energy Program Fossil Energy Program Fossil Energy Program Fossil Energy Program

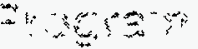

$2-30 \%$

2 rages

$2: \sin$

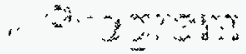

"

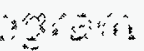

$3 y+20$ ?

$\because 4 y^{2}$

$\cos 200$

-reger

Mram

P. ogram

arsers

argeteren

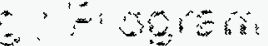

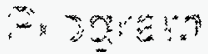

$=3+15$

$2+20 x$

$=-3: 3$ by S. H. D. Lee, K. Natesan, and W. M. Swift

\section{Testing of Candidate Materials for Their Resistance to Alkali-vapor Adsorption in PFBC and Gasification Environments}

Argonne National Laboratory, Argonne, Illinois 60439

operated by The University of Chicago

for the United States Department of Energy under Contract W-31-109-Eng-38

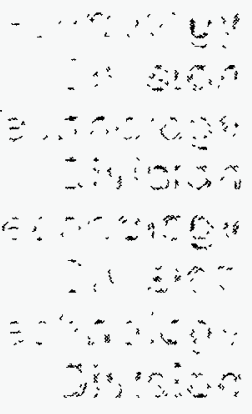


Argonne National Laboratory, with facilities in the states of Illinois and Idaho, is owned by the United States government, and operated by The University of Chicago under the provisions of a contract with the Department of Energy.

\section{DISCLAIMER}

This report was prepared as an account of work sponsored by an agency of the United States Government. Neither the United States Government nor any agency thereof, nor any of their employees, makes any warranty, express or implied, or assumes any legal liability or responsibility for the accuracy, completeness, or usefulness of any information, apparatus, product, or process disclosed, or represents that its use would not infringe privately owned rights. Reference herein to any specific commercial product, process, or service by trade name, trademark, manufacturer, or otherwise, does not necessarily constitute or imply its endorsement, recommendation, or favoring by the United States Government or any agency thereof. The views and opinions of authors expressed herein do not necessarily state or reflect those of the United States Government or any agency thereof.

Reproduced from the best available copy.

Available to DOE and DOE contractors from the

Office of Scientific and Technical Information

P.O. Box 62

Oak Ridge, TN 37831

Prices available from (615) 576-8401

Available to the public from the

National Technical Information Service

U.S. Department of Commerce

5285 Port Royal Road

Springfield, VA 22161 


\section{DISCLAIMER}

Portions of this document may be illegible in electronic image products. Images are produced from the best available original document. 
Distribution Category:

Fluidized Bed Combustion

(UC-103)

\begin{abstract}
ANL/FE-95-01
ARGONNE NATIONAL LABORATORY

9700 South Cass Avenue

Argonne, IL 60439

TESTING OF CANDIDATE MATERIALS FOR

THEIR RESISTANCE TO ALKALI-VAPOR

ADSORPTION IN PFBC AND GASIFICATION ENVIRONMENTS
\end{abstract}

FINAL REPORT

by

S. H. D. Lee, K. Natesan, ${ }^{\dagger}$ and W. M. Swift

Chemical Technology Division

${ }^{\dagger}$ Energy Technology Division

August 1995

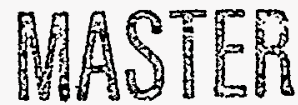




\section{-}




\section{TABLE OF CONTENTS}

Page

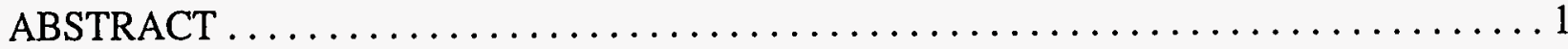

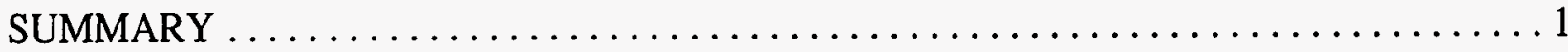

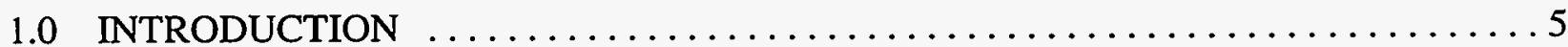

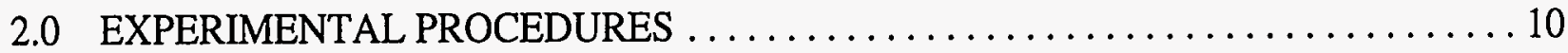

2.1 Candidate Materials and Their Preparation $\ldots \ldots \ldots \ldots \ldots \ldots \ldots \ldots \ldots \ldots \ldots$

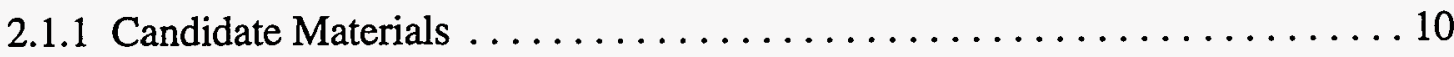

2.1.2 Preparation of Specimen Coupons $\ldots \ldots \ldots \ldots \ldots \ldots \ldots \ldots \ldots \ldots \ldots \ldots \ldots \ldots$

2.2 Test Equipment and Procedures $\ldots \ldots \ldots \ldots \ldots \ldots \ldots \ldots \ldots \ldots \ldots \ldots \ldots \ldots \ldots \ldots \ldots \ldots$

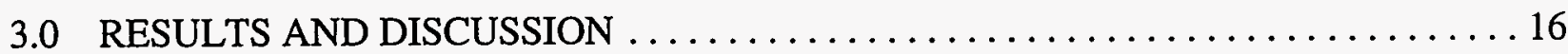

3.1 Tests in Baseline Simulated PFBC Off-Gas $\ldots \ldots \ldots \ldots \ldots \ldots \ldots \ldots \ldots$

3.2 Tests in Simulated PFBC Off-Gas Containing $\mathrm{NaCl}$ Vapor $\ldots \ldots \ldots \ldots \ldots \ldots 21$

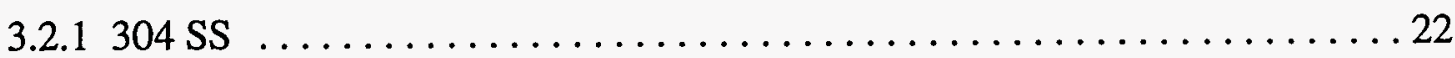

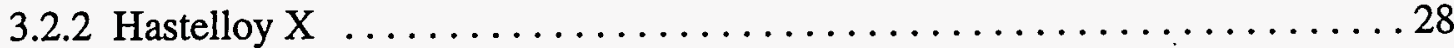

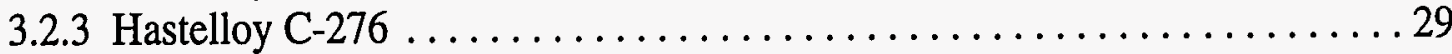

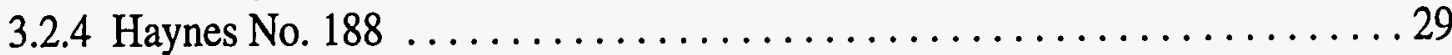

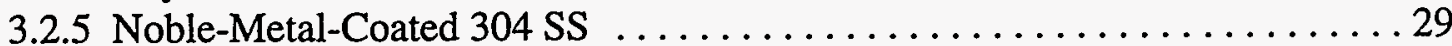

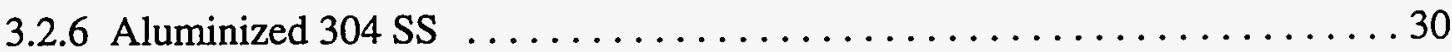

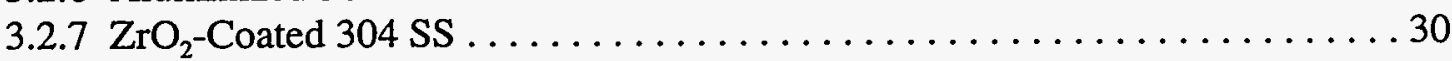

3.3 Tests in Baseline Simulated Gasification Fuel Gas .................. 31

3.4 Test in Simulated Gasification Fuel Gas Containing $\mathrm{NaCl}$ Vapor ........... 32

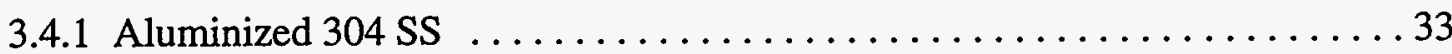

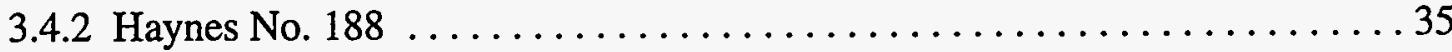

4.0 CONCLUSIONS AND RECOMMENDATIONS $\ldots \ldots \ldots \ldots \ldots \ldots \ldots \ldots \ldots \ldots \ldots$

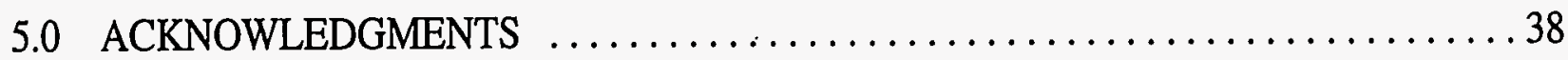

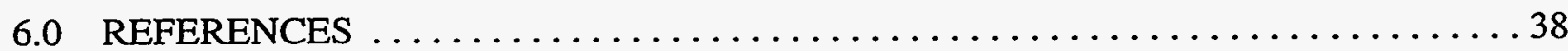




\section{LIST OF FIGURES}

No.

Title

$\underline{\text { Page }}$

1. Scale Thickness and Intergranular Penetration Data for Bare Alloys

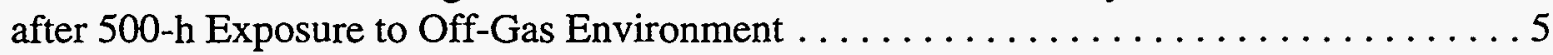

2. Scale Thickness and Intergranular Penetration Data for

$\mathrm{CaSO}_{4}$-Coated Alloys after 500- and 2000-h Exposures to

Off-Gas Environment at Metal Temperatures of $704^{\circ} \mathrm{C}$ and $593^{\circ} \mathrm{C} \ldots \ldots \ldots \ldots 6$

3. Relative Corrosion Loss for Base Alloys in 1 vol\% $\mathrm{SO}_{2}$, $4 \mathrm{vol} \% \mathrm{O}_{2}$, and $5 \mathrm{wt} \%$ Alkali Sulfate

4. Relationship Between Chromium Content of Alloys and Relative Corrosion Loss in 4 vol\% $\mathrm{O}_{2}$ Off-Gas at $700^{\circ} \mathrm{C}$

5. Schematic of Pressurized $\mathrm{NaCl}-\mathrm{KCl}$-Vapor Generation Unit Integrated with Ames On-Line, Real-Time Alkali Analyzer

6. Measured Sodium and Potassium Concentrations in the Gas Stream for Test of Type 304 Stainless Steel Sampling Line at $840-950^{\circ} \mathrm{C}$ and $9.2 \mathrm{~atm}$ Absolute ......9

7. Auger Electron Spectroscopy and Depth Profile Analysis for Pt-Coated 304 SS Specimen

8. SEM Micrographs of Cross Sections of Aluminized 304 SS in the as-Aluminized Condition, and after Exposure to Air at $1000^{\circ} \mathrm{C}$ for 2 and $50 \mathrm{~h}$.

9. Elemental Concentration Profiles for $\mathrm{Al}, \mathrm{Cr}, \mathrm{Fe}, \mathrm{Ni}$, and $\mathrm{O}$ in the Near-Surface Regions of Aluminized 304 SS . . . . . . . . . . . . . . . 14

10. TGA Setup for Studying Alkali-Vapor Capture by Metallic Materials $\ldots \ldots \ldots \ldots \ldots$

11. SEM Micrographs of Cross Sections of Test Specimens after Exposure to Baseline Simulated PFBC Off-Gas (No NaCl Vapor) $\ldots \ldots \ldots \ldots \ldots 18$

12. EDX Analysis of Hastelloy X, Hastelloy C-276, and Haynes No. 188 after Exposure to Baseline Simulated

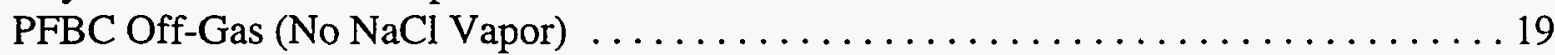

13. EDX Analysis of Scales of Pt-Coated 304 SS, Au-Coated 304 SS, and Ag-Coated 304 SS after Exposure to Baseline Simulated

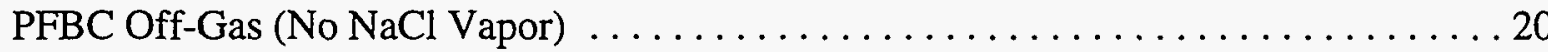




\section{LIST OF FIGURES (contd)}

№.

Title

Page

14. Elemental Concentration Profiles for $\mathrm{Al}, \mathrm{Cr}, \mathrm{Fe}, \mathrm{Ni}$, and $\mathrm{O}$ in the Pretreated Aluminized 304 SS after Exposure to Baseline Simulated PFBC Off-Gas (No NaCl Vapor) $\ldots \ldots \ldots \ldots \ldots \ldots \ldots \ldots 21$

15. SEM Micrographs of Surfaces and Cross Sections of 304 SS and Hastelloy $X$ after Exposure to Simulated PFBC Off-Gas Containing NaCl Vapor .............23

16. SEM Micrographs of Surfaces and Cross Sections of Hastelloy C-276 and Haynes No. 188 after Exposure to Simulated PFBC Off-Gas

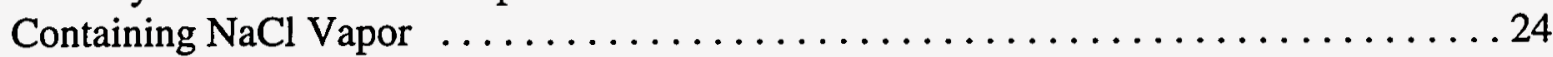

17. SEM Micrographs of Surfaces and Cross Sections of Pt-Coated, $\mathrm{Au}-\mathrm{Coated}$, and $\mathrm{Ag}$-Coated $304 \mathrm{SS}$ after Exposure to

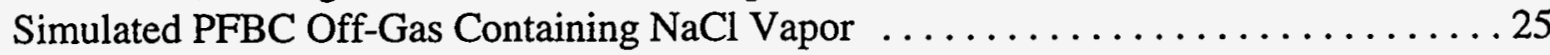

18. SEM Micrographs of Surfaces and Cross Sections of Aluminized 304 SS and $\mathrm{ZrO}_{2}$-Coated $304 \mathrm{SS}$ after Exposure to Simulated PFBC Off-Gas

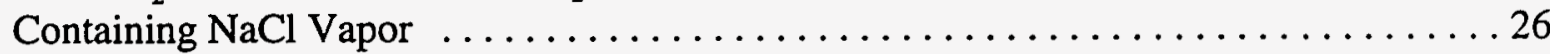

19. SEM Micrographs of Surface and Cross Section of Aluminized 304 SS after Exposure to Baseline Simulated Gasification Fuel Gas (No $\mathrm{NaCl}$ Vapor) . . . . . . . . 32

20. EDX Spectra of the Surface of Aluminized 304 SS after Exposure to Baseline Simulated Gasification Fuel Gas (No $\mathrm{NaCl}$ Vapor) ........... 33

21. SEM Micrographs of Surface and Cross Section and EDX Spectra for Locations A and B on the Surface of Haynes No. 188 after Exposure to Baseline Simulated Gasification Fuel Gas (No $\mathrm{NaCl}$ Vapor) ........... 34

22. SEM Micrographs of Surface and Cross Section and EDX Spectra for Locations A, B, and C on the Surface of Aluminized 304 SS after Exposure to Simulated Gasification Fuel Gas Containing NaCl Vapor ............ 36

23. SEM Micrographs of Surface and Cross Section and EDX Spectra for Locations A and B on the Surface of Haynes No. 188 after Exposure to Simulated Gasification Fuel Gas Containing $\mathrm{NaCl}$ Vapor ............ 37 


\section{LIST OF TABLES}

No.

$\underline{\text { Title }}$

$\underline{\text { Page }}$

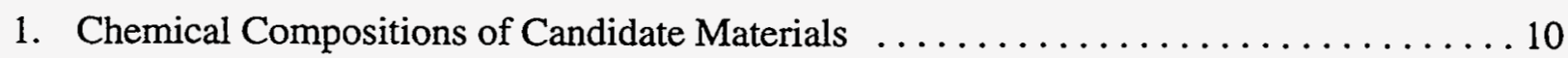

2. Experimental Conditions for Atmospheric TGA Tests of Candidate

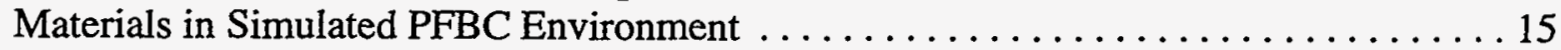

3. Total Weight Change of Candidate Materials Tested in Baseline Simulated PFBC Off-Gas (No NaCl Vapor) $\ldots \ldots \ldots \ldots \ldots \ldots \ldots \ldots \ldots$

4. Total Weight Change of Candidate Materials Tested in Simulated PFBC Off-Gas Containing $\mathrm{NaCl}$ Vapor

5. AES Surface Concentrations in Coupon Specimens Exposed to Simulated PFBC Off-Gas Containing NaCl Vapor

6. AES Surface Concentrations at a Depth of $2700 \AA$ in Coupon Specimens Exposed to Simulated PFBC Off-Gas Containing $\mathrm{NaCl}$ Vapor $\ldots \ldots \ldots \ldots \ldots \ldots 28$

7. Total Weight Gain of Aluminized 304 SS and Haynes No. 188 under Baseline Simulated Gasification Fuel Gas (No NaCl Vapor)

8. Total Weight Gain of Aluminized 304 SS and Haynes No. 188 under Simulated Gasification Fuel Gas Containing $\mathrm{NaCl}$ Vapor ... 


\title{
TESTING OF CANDIDATE MATERIALS FOR THEIR RESISTANCE TO ALKALI-VAPOR ADSORPTION IN PFBC AND GASIFICATION ENVIRONMENTS
}

\author{
Final Report
}

by

S. H. D. Lee, K. Natesan, and W. M. Swift

\begin{abstract}
Under the auspices of the U.S. Department of Energy through Morgantown Energy Technology Center, laboratory-scale studies were performed to identify metallic material(s) having no, or limited, affinity for alkali vapors in an environment of either the off-gas from pressurized fluidized-bed combustion (PFBC) or the fuel gas from coal gasification. Such materials would be potential candidates for use as components in advanced coal-utilization systems. The following materials were tested for adsorption of $\mathrm{NaCl}$ vapor at $870-875^{\circ} \mathrm{C}$ and atmospheric pressure in a simulated $\mathrm{PFBC}$ off-gas (oxidizing) doped with 80 ppmW NaCl vapor: iron-based Type 304 stainless steel (304 SS), nickel-based Hastelloy C-276 and Hastelloy X alloys, cobalt-based Haynes No. 188 alloy, noble-metal-coated $304 \mathrm{SS}$, aluminized $304 \mathrm{SS}$, and $\mathrm{ZrO}_{2}$-coated $304 \mathrm{SS}$. The Haynes No. 188 alloy and the aluminized 304 SS were also tested for their $\mathrm{NaCl}$ vapor adsorption in a simulated gasification fuel gas (reducing) under the same test conditions as in the PFBC off-gas test. After $100 \mathrm{~h}$ of testing, the specimens were analyzed with a scanning electron microscope equipped with an energy dispersive X-ray analyzer, and by an Auger electron spectrometer. The test materials showed various degrees of $\mathrm{NaCl}$-vapor adsorption after exposure to the PFBC off-gas. The aluminized $304 \mathrm{SS}$ had the least tendency to adsorb $\mathrm{NaCl}$ vapor, as well as an excellent resistance to corrosion as a result of the formation of a protective layer of $\mathrm{Al}_{2} \mathrm{O}_{3}$ on its surface. In the reducing environment, however, the aluminized $304 \mathrm{SS}$ was badly corroded by $\mathrm{H}_{2} \mathrm{~S}$ attack. The Haynes No. 188 showed virtually no $\mathrm{NaCl}$-vapor adsorption and only limited $\mathrm{H}_{2} \mathrm{~S}$ attack. Based on these results, we recommend further long-term parametric studies to quantitate alkali-vapor adsorption as a function of operating variables for (1) the aluminized 304 SS in the PFBC off-gas environment and (2) the Haynes No. 188 in the gasification fuel gas environment.
\end{abstract}

\section{SUMMARY}

Alkali vapors (chlorides, hydroxides, and sulfates of sodium and potassium) are present in the high-temperature/high-pressure (HTHP) off-gas of advanced coal utilization systems, such 
as direct coal-fired turbines, pressurized fluidized-bed combustion (PFBC) systems, and integrated coal gasification combined-cycle systems. These vapors are a source of concern because of their deleterious effects on components of the HTHP process; for example, they cause hot corrosion of fire-side boiler tubes and gas turbine hardware. The objective of this study is to identify non-alkali-adsorbing material(s) (if any) that may be suitable components for advanced coal-utilization systems. One specific use for such a material is in the gaseous sampling line for an on-line alkali analyzer. An inert sampling line is needed to ensure analytical accuracy.

In this study, nine candidate materials were tested for their $\mathrm{NaCl}$-vapor adsorption in a simulated PFBC off-gas environment, namely, an iron-based Type 304 stainless steel (304 SS), two nickel-based Hastelloy C-276 and Hastelloy X alloys, a cobalt-based Haynes No. 188 alloy, a platinum-coated 304 SS, a gold-coated 304 SS, a silver-coated 304 SS, an aluminized 304 SS, and a $\mathrm{ZrO}_{2}$-coated $304 \mathrm{SS}$. Haynes No. 188 and aluminized $304 \mathrm{SS}$ were also tested for their $\mathrm{NaCl}$-vapor adsorption in a simulated gasification fuel gas. Tests of the metallic materials were conducted using prepared coupons. Those of 304 SS, Hastelloy X, Hastelloy C-276, and Haynes No. 188 were finished by polishing with 4000 -grit $\mathrm{SiC}$ paper, cleaned in an ultrasonic water bath, and finally rinsed with alcohol. For coupons of Pt-, Au-, and Ag-coated 304 SS, a finished $304 \mathrm{SS}$ coupon was sputter-deposited with $\mathrm{Pt}, \mathrm{Au}$, or $\mathrm{Ag}$. The deposited layers were approximately $1 \mu \mathrm{m}$ thick. To prepare the aluminized specimen, a finished $304 \mathrm{SS}$ coupon was aluminized by a commercial vendor (Alon Processing, Inc., PA). The $\mathrm{ZrO}_{2}$-coated $304 \mathrm{SS}$ coupon was prepared by depositing (1) a bond coat of (Ni, Co) $\mathrm{Cr} \mathrm{Al} \mathrm{Y}$ and (2) an external ceramic coating of $\mathrm{ZrO}_{2}$ by use of a thermal spray process. The bond layer was about $100 \mu \mathrm{m}$ thick, and the $\mathrm{ZrO}_{2}$ coating, about $500 \mu \mathrm{m}$.

For experimental testing, specimen coupons were suspended in a thermogravimetric analyzer (TGA) setup and exposed to the simulated PFBC off-gas, or the gasification fuel gas, at $870-875^{\circ} \mathrm{C}$ and atmospheric pressure for $100 \mathrm{~h}$. The simulated PFBC off-gas contained $3.1 \% \mathrm{O}_{2}$, $14.7 \% \mathrm{CO}_{2}, 2.0 \% \mathrm{H}_{2} \mathrm{O}$ vapor, $880 \mathrm{ppmV} \mathrm{SO}$, either 0 or $80 \mathrm{ppmW} \mathrm{NaCl}$ vapor, and the balance $\mathrm{N}_{2}$. The simulated gasification fuel gas contained $20 \% \mathrm{H}_{2}, 19 \% \mathrm{CO}, 5 \% \mathrm{CH}_{4}, 0.2 \% \mathrm{H}_{2} \mathrm{~S}, 12 \%$ $\mathrm{CO}_{2}, 2 \% \mathrm{H}_{2} \mathrm{O}$ vapor, either 0 or $80 \mathrm{ppmW} \mathrm{NaCl}$ vapor, and the balance $\mathrm{N}_{2}$. At the end of the test period, coupons were analyzed by scanning electron microscopy (SEM) using a microscope equipped with an energy dispersive X-ray (EDX) analyzer to examine corrosion of the candidate materials and $\mathrm{NaCl}$-vapor adsorption. Near-surface regions of selected specimens were also analyzed by Auger electron spectroscopy (AES).

A set of all coupons (except the $\mathrm{ZrO}_{2}$-coated specimen) was first tested in a baseline $\mathrm{PFBC}$ off-gas containing no $\mathrm{NaCl}$ vapor. At the end of the test, all the originally shiny coupon specimens (304 SS, Hastelloy X, Hastelloy C-276, Haynes No. 188, Pt-coated 304 SS, Au-coated $304 \mathrm{SS}$, and Ag-coated $304 \mathrm{SS}$ ) had formed black scales. The scale was predominantly $\mathrm{Cr}_{2} \mathrm{O}_{3}$ in the 304 SS, Hastelloy X, and Haynes No. 188 specimens, whereas the oxide scale in Hastelloy $\mathrm{C}-276$ contained $\mathrm{Cr}, \mathrm{Fe}$, and $\mathrm{Ni}$. The lower concentration of chromium (15.5 wt\%) in Hastelloy $\mathrm{C}-276$ is not sufficient to form pure chromia scale at temperatures of $870-875^{\circ} \mathrm{C}$. In the case of the Pt-, Au-, and Ag-coated 304 SS coupons, the sputter deposit of the noble metals did not prevent outward diffusion of substrate elements ( $\mathrm{Cr}$ and/or $\mathrm{Fe}$ ) and subsequent oxidation of these elements. The oxide scale on the Pt-coated 304 SS was almost pure $\mathrm{Cr}_{2} \mathrm{O}_{3}$, that on the Au-coated $304 \mathrm{SS}$ was $(\mathrm{Cr}, \mathrm{Fe})$ oxide, and that on the Ag-coated sample was iron oxide. The as-received 
aluminized $304 \mathrm{SS}$ specimen was pretreated in air at $1000^{\circ} \mathrm{C}$ for $50 \mathrm{~h}$ to form a continuous $\mathrm{Al}_{2} \mathrm{O}_{3}$ scale on the surface before exposure to the simulated PFBC off-gas for $100 \mathrm{~h}$. This scale remained intact throughout exposure. No sulfur was detected in the scale or the alloy substrate in any of the coupons.

The second set of coupon specimens was tested in the simulated PFBC off-gas containing $80 \mathrm{ppmW} \mathrm{NaCl}$ vapor. Black scales formed on the specimens as in the baseline experiment. The black scales of the 304 SS, Hastelloy X, Haynes No. 188, Pt-coated 304 SS, and Au-coated 304 SS specimens appeared visually firm and smooth; however, the Hastelloy C-276 and Ag-coated 304 SS specimens became severely corroded when exposed to the $\mathrm{NaCl}$ vapor, with the black scales peeling off the specimens.

Results of the SEM/EDX analyses of the exposed 304 SS coupon suggested that a layer of $\mathrm{Na}_{2} \mathrm{SO}_{4}$ was distributed on a thin oxide scale. The captured sodium could also have reacted with the base metal to form complex ( $\mathrm{Na}, \mathrm{Cr}, \mathrm{Mn}, \mathrm{Fe}$ ) oxides as reaction products. The AES analyses indicated sodium concentrations of 26.7 and 11.8 at.\% on the surface and 21.1 and 4.2 at.\% at a depth of $2700 \AA$ for two specimens exposed for 100 and $90 \mathrm{~h}$, respectively. Chlorine (2.8 at.\%) was also detected on the surface of one specimen, indicating the adsorption of $\mathrm{NaCl}$ vapor on the $\mathrm{Cr}_{2} \mathrm{O}_{3}$. It is possible that $\mathrm{NaCl}$ vapor was initially adsorbed on the surface and then gradually reacted with adsorbed $\mathrm{SO}_{2}, \mathrm{O}_{2}$, and $\mathrm{H}_{2} \mathrm{O}$ vapor to form the $\mathrm{Na}_{2} \mathrm{SO}_{4}$ layer that was observed by SEM.

The SEM/EDX analyses of the Hastelloy $\mathrm{X}$ coupon also suggested that a $\mathrm{Na}_{2} \mathrm{SO}_{4}$ layer was deposited on the oxide scale. The AES analyses of the specimen showed similarly high sodium concentrations on the surface (28.6 at.\%) and at $2700 \AA$ (20.3 at.\%) as were measured for the 304 SS specimen. The AES analysis also detected 2.2 at.\% chlorine on the surface of the specimen. In contrast to Hastelloy X, the Hastelloy C-276 coupon was severely corroded and showed evidence of substantial internal sulfidation after exposure. This enhanced corrosion can be attributed to the lower chromium content $(15.5 \mathrm{wt} \%$ ) of the alloy compared to the Hastelloy $\mathrm{X}$ (22.0 wt\%). As in the $304 \mathrm{SS}$ and the Hastelloy X specimens, a layer of $\mathrm{Na}_{2} \mathrm{SO}_{4}$ was observed on the oxide scale surface of the Haynes No. 188 coupon, but the AES analysis showed lower sodium concentrations, both on the surface (19.0 at.\%) and at $2700 \AA$ (11.6 at.\%), than those measured in 304 SS and the Hastelloy X. A trace amount ( 0.8 at.\%) of chlorine was also detected on the surface of the Haynes No. 188 specimen.

The SEM/EDX analyses of the Pt-, Au-, and Ag-coated 304 SS coupons showed that the $\mathrm{Pt}$-coated specimen developed a thin, predominantly $\mathrm{Cr}_{2} \mathrm{O}_{3}$ scale, whereas the scale on the $\mathrm{Au}$ - and Ag-coated specimens was mainly iron oxide. Substantial segregation of $\mathrm{Au}$ and $\mathrm{Ag}$ was observed at the scale/alloy interface, indicating that these coatings do not act as barriers to outward diffusion and subsequent oxidation of iron from the bulk alloy. Some sulfides were observed in the interior of all three coupons. The AES analyses showed sodium concentrations of 20.2, 16.1, and 15.3 at.\% on the surfaces of the Pt-, Au-, and Ag-coated specimens, respectively, and lower concentrations (10.6, 7.8 , and 7.7 at.\%) at $2700 \AA$.

As in the baseline PFBC tests, SEM/EDX analyses of two aluminized 304 SS specimens after 100 - and $150-\mathrm{h}$ exposures to the $\mathrm{NaCl}$-vapor-bearing $\mathrm{PFBC}$ environment showed that the 
continuous $\mathrm{Al}_{2} \mathrm{O}_{3}$ scale developed during the pretreatment remained intact. No sulfur was detected in the scale or the alloy substrate. The AES analyses of the two specimens showed sodium concentrations of 6.1 and 8.5 at.\% on the surface, and 14.3 and 10.0 at.\% at a depth of $2700 \AA$, after 100 and $150 \mathrm{~h}$, respectively. For the $\mathrm{ZrO}_{2}$-coated $304 \mathrm{SS}$ specimen, the SEM/EDX analyses indicated a fairly uniform deposit layer of $\mathrm{Na}_{2} \mathrm{SO}_{4}$, with a globular shape $30 \mu \mathrm{m}$ in diameter. The deposit exhibited some porosity accompanied by chipping and cracking of the coating in a few areas. In agreement with the SEM/EDX analyses, the AES analysis of the specimen showed relatively high sodium concentrations, i.e. 26.7 at.\% on the surface and 24.0 at. $\%$ at $2700 \AA$.

Of the nine candidate materials tested in the simulated PFBC off-gas (oxidizing), the aluminized 304 SS and the Haynes No. 188 showed both good resistance to corrosion and low sodium capture; therefore, these two materials were selected for further testing in the simulated gasification fuel gas (reducing). In the baseline test (no NaCl vapor), the $\mathrm{Al}_{2} \mathrm{O}_{3}$ scale that originally formed on the aluminized $304 \mathrm{SS}$ during pretreatment (in air at $1000^{\circ} \mathrm{C}$ for $50 \mathrm{~h}$ ) showed evidence of $\mathrm{H}_{2} \mathrm{~S}$ attack in isolated regions, forming $(\mathrm{Cr}, \mathrm{Mn}, \mathrm{Fe})$ sulfides. By contrast, the Haynes No. 188 specimen formed a continuous, uniform black scale on the surface. The EDX analysis of the specimen indicated that the scale consisted of chromium-rich $(\mathrm{Cr}, \mathrm{Mn}, \mathrm{Fe})$ oxides containing a trace amount of sulfur.

Finally, the aluminized 304 SS and the Haynes No. 188 specimens were tested together at $870-875^{\circ} \mathrm{C}$ for $70 \mathrm{~h}$ in the simulated gasification fuel gas containing $80 \mathrm{ppmW} \mathrm{NaCl}$ vapor. The aluminized 304 SS specimen became badly corroded, and EDX analysis of the specimen clearly showed the formation of $(\mathrm{Cr}, \mathrm{Mn}, \mathrm{Fe})$ oxides and sulfides in isolated areas of the surface. The formation of these corrosion products undermined the $\mathrm{Al}_{2} \mathrm{O}_{3}$ scale originally developed on the surface, causing it to spall off. The EDX analysis also showed the presence of sodium along with sulfur on the surface of the $\mathrm{Al}_{2} \mathrm{O}_{3}$ scale, suggesting the affinity of the $\mathrm{Al}_{2} \mathrm{O}_{3}$ for sodium adsorption. By contrast, a continuous, uniform black scale of chromium-rich ( $\mathrm{Cr}, \mathrm{Mn}, \mathrm{Fe}$ ) oxides was formed on the surface of the Haynes No. 188 specimen. Some sulfur was shown in isolated locations, but virtually no sodium was found, indicating a lack of sorption affinity of the oxide scale for $\mathrm{NaCl}$ vapor. This is in contrast to the $\mathrm{Cr}_{2} \mathrm{O}_{3}$ scale developed in the oxidizing PFBC offgas, on which $\mathrm{NaCl}$ vapor adsorbed and gradually converted to $\mathrm{Na}_{2} \mathrm{SO}_{4}$. 


\subsection{INTRODUCTION}

In advanced coal-utilization systems, such as direct coal-fired turbines, pressurized fluidized-bed combustion (PFBC), and integrated coal gasification combined-cycle systems, the high-temperature/high-pressure (HTHP) off-gas is expanded through a gas turbine to recover thermal energy for improved system efficiency. Alkali vapors (chlorides, hydroxides, and sulfates of sodium and potassium) are present in the HTHP off-gas of these systems ${ }^{1-3}$ and are known to cause hot corrosion of fire-side boiler tubes and gas turbine hardware. ${ }^{4,5}$ Because of their deleterious effect on the HTHP process component materials, alkali vapors have been a cause of concern and their removal from the HTHP off-gas of advanced coal-utilization systems has been the subject of many studies. ${ }^{2,6-9}$

A literature review revealed information about the effect of alkali on metallic materials. Corrosion of structural materials exposed to the effluent from fluidized-bed combustion (FBC) can occur by gas phase oxidation/sulfidation or deposit-induced liquid-phase corrosion. The former can be minimized by using materials that are oxidation resistant at service temperatures of interest. The FBC effluent is generally oxidizing and has $\mathrm{PO}_{2}$ values in the range of $10^{-2}-10^{-4} \mathrm{~atm}$. Under these conditions, the sulfur in the gas phase will be present predominantly in the form of $\mathrm{SO}_{2}$ at concentrations of 100-2000 ppmV. Extensive studies have been conducted on the corrosion performance of structural alloys exposed to $\mathrm{SO}_{2}$-containing gas atmospheres, and the results of two such studies ${ }^{10.11}$ are shown in Figs. 1 and 2. Figure 1 shows the scale thickness and alloy penetration data for carbon steel, low-alloy ferritic steels, and high-chromium

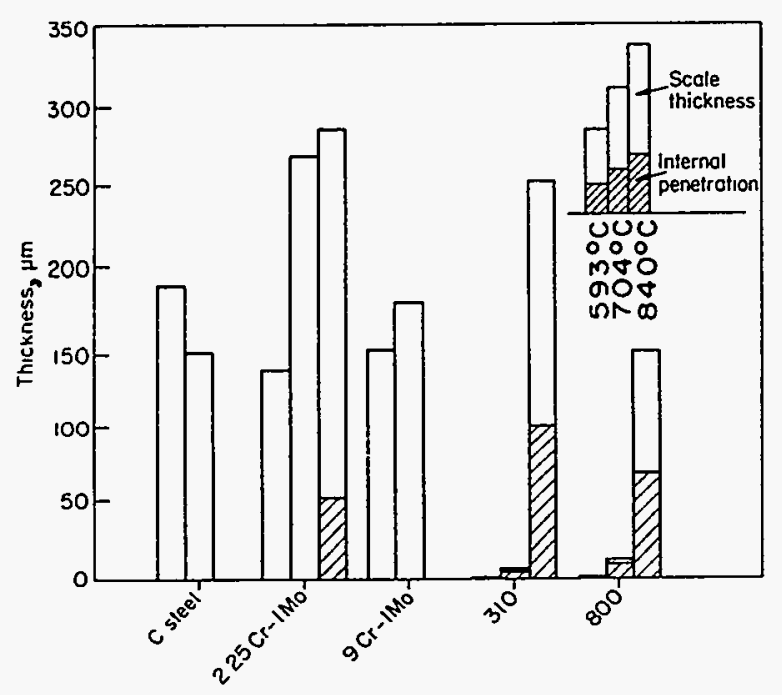

Fig. 1.

Scale Thickness and Intergranular Penetration Data for Bare Alloys after 500-h Exposure to Off-Gas Environment. ${ }^{10,11}$ The numbers 310 and 800 correspond to Type 310 Stainless Steel and Alloy 800 . C Steel and $9 \mathrm{Cr}-1 \mathrm{Mo}$ Steel were not tested at $840^{\circ} \mathrm{C}$.

austenitic alloys when exposed to an oxidizing environment containing approximately 1700 ppmV of $\mathrm{SO}_{2}$ at temperatures of 593,704 , and $840^{\circ} \mathrm{C}\left(1100,1300,1544^{\circ} \mathrm{F}\right.$, respectively). Figure 2 shows the scale thickness and penetration data for the $\mathrm{CaSO}_{4}$-coated alloys exposed to the $\mathrm{SO}_{2}$-containing gas mixture. The results show that the scaling rates for the high-chromium alloys are in the range of 2-8 mils per year, based on parabolic kinetics. 

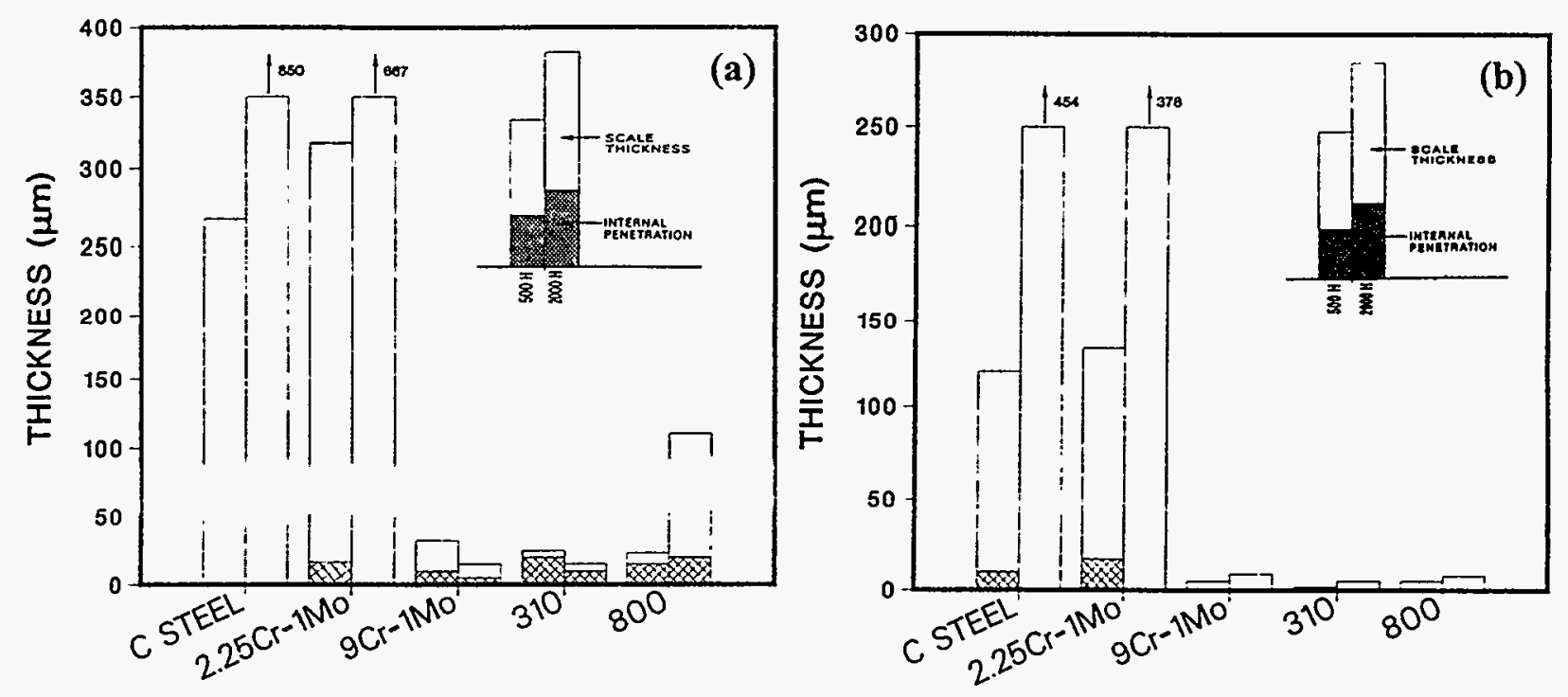

Fig. 2. Scale Thickness and Intergranular Penetration Data for $\mathrm{CaSO}_{4}$-Coated Alloys after 500- and 2000-h Exposures to Off-Gas Environment at Metal Temperatures of (a) $704^{\circ} \mathrm{C}$ and (b) $593^{\circ} \mathrm{C}^{10,11}$

On the other hand, deposit-induced corrosion of materials by alkali is an accelerated type of attack, influenced by the vaporization and condensation of small amounts of impurities, such as $\mathrm{Na}, \mathrm{K}, \mathrm{Cl}$, and $\mathrm{S}$ (or their compounds), that are present in the coal feedstock. Corrosion of metallic materials in the presence of liquid $\mathrm{Na}_{2} \mathrm{SO}_{4}$, either by itself or in combination with $\mathrm{NaCl}$, has been a problem in gas turbines; this corrosion process has been termed "hot corrosion" to differentiate it from gas-phase sulfidation attack. Two types of hot corrosion have been identified ${ }^{12-14}$; Type I, operative in the range $800-950^{\circ} \mathrm{C}$, and Type II, operative over the range $600-750^{\circ} \mathrm{C}$.

Type I hot corrosion can be split into an initiation (or incubation) stage and a propagation stage. The process, in general, requires the presence of liquid $\mathrm{Na}_{2} \mathrm{SO}_{4}$ (melting point $884^{\circ} \mathrm{C}$ ) on the metal surface. In the initiation stage, the protective oxide scale dissolves by a basic fluxing mechanism and the corrosion rates are generally low. In the propagation stage, when the protective oxide has been destroyed and is not able to reform, the alloy is subjected to sulfidation by inward diffusion of sulfur, leading to accelerated corrosion rates.

Type II hot corrosion, also known as low-temperature hot corrosion, involves the eutectics of base metal sulfates and sodium sulfate and, therefore, occurs predominantly at lower temperatures, especially in the effluent of the FBC environment. For example, the eutectic temperature for sodium sulfate-cobalt sulfate is $565^{\circ} \mathrm{C}$. In this type of corrosion, the transient oxides of cobalt or nickel (which nucleate in the early stage of oxidation in chromium- and aluminum-containing superalloys) react with sodium sulfate to form eutectic salts that prevent formation of protective chromia or alumina. The corrosion process is strongly dependent on the partial pressure of sulfur trioxide at the melt/scale interface, but the process occurs at much lower temperatures than the melting point of sodium sulfate. 
Extensive studies ${ }^{12-14}$ were conducted to evaluate the hot-corrosion behavior of nickel-based superalloys and coatings in environments typical of gas turbines. The major thrust in these studies was to correlate the corrosion behavior of the alloys with various parameters, such as test temperature, the salt $\left(\mathrm{Na}_{2} \mathrm{SO}_{4}\right)$ chemistry, salt film thickness, gas composition, and alloying element additions. The presence of $\mathrm{NaCl}$ in the environment can lead. to formation of $\mathrm{Na}_{2} \mathrm{SO}_{4}$ via the reaction

$$
2 \mathrm{NaCl}+\mathrm{SO}_{3}+1 / 2 \mathrm{O}_{2}=\mathrm{Na}_{2} \mathrm{SO}_{4}+\mathrm{Cl}_{2}
$$

which can contribute to hot corrosion. In general, it was found that high-chromium alloys exhibited better resistance to hot corrosion. In addition to chromium, elements such as $\mathrm{Al}$, $\mathrm{Ti}$, and $\mathrm{W}$ seemed to impart better resistance. Elements such as Mo and $\mathrm{C}$ had a deleterious effect on the corrosion resistance.

Although extensive studies have been conducted on hot-corrosion resistance of nickel-based superalloys, very little is known about the performance of iron-based heat-resistant alloys. Some corrosion studies were conducted on iron-based materials in the presence of synthetic coal ash with addition of $\mathrm{Na}_{2} \mathrm{SO}_{4}$ and/or $\mathrm{K}_{2} \mathrm{SO}_{4}$, in support of material evaluation for superheaters and reheaters of coal-fired boilers. ${ }^{12}$ The results, based on 100-h tests in simulated combustion atmospheres with synthetic coal ash deposits, showed increased corrosion resistance with increased chromium content of the alloys up to 20-25 wt\%. Figures 3 and 4 show the relative corrosion loss data, and the relationship between chromium content and relative corrosion loss for several of the alloys tested. ${ }^{15}$

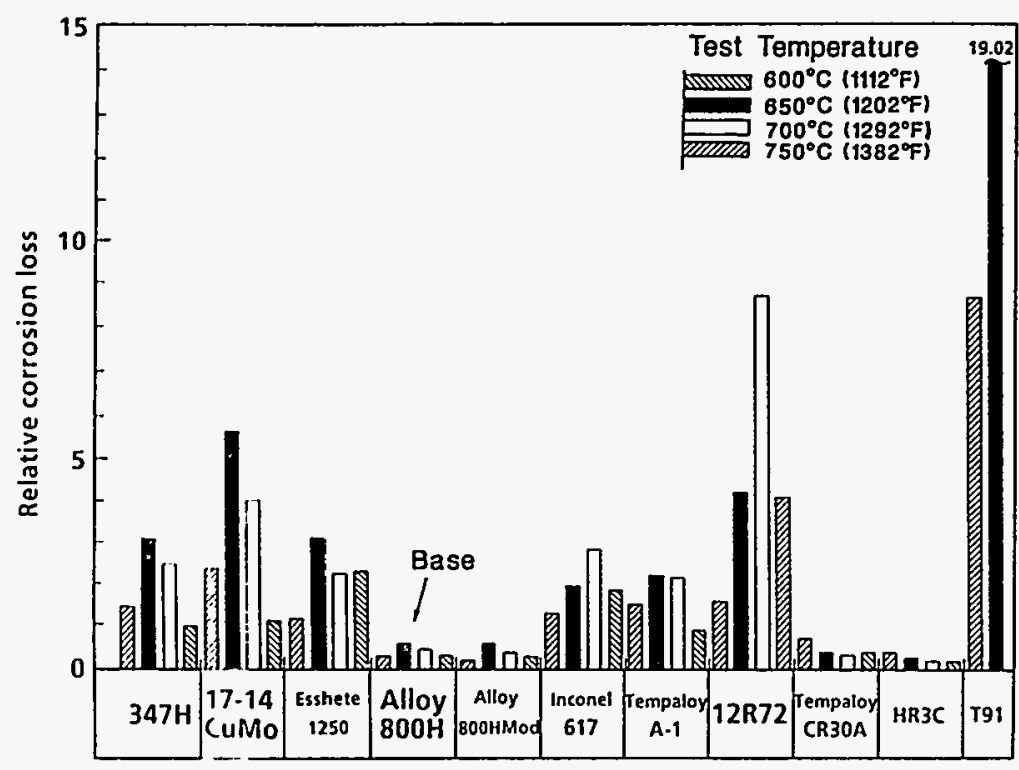

Fig. 3.

Relative Corrosion Loss for Base Alloys in 1 vol\% $\mathrm{SO}_{2}$, 4 vol\% $\mathrm{O}_{2}$, and $5 \mathrm{wt} \%$ Alkali Sulfate ${ }^{15}$

Predicting the evolution of alkalis from the combustion and gasification of coal has been the goal of many thermodynamic studies. ${ }^{1-3.16-19}$ Sodium and potassium chlorides are suggested to be major gaseous alkali carriers in PFBC off-gas. ${ }^{1,3,16}$ Alkali hydroxide vapors may exist to a 


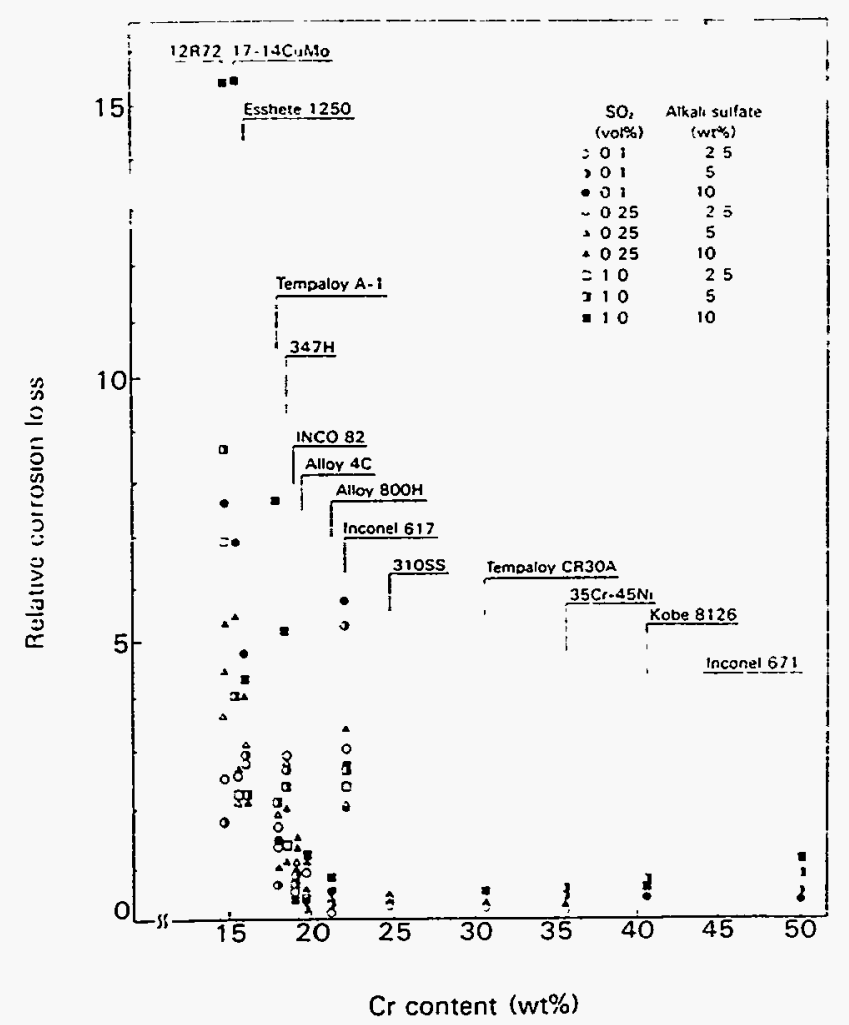

Fig. 4.

Relationship Between Chromium Content of Alloys and Relative Corrosion Loss in 4 vol\% $\mathrm{O}_{2}$ Off-Gas at $700^{\circ} \mathrm{C}^{15}$

lesser extent. ${ }^{3}$ These chlorides and hydroxides can substantially convert to condensed-phase sulfate by reacting with $\mathrm{SO}_{2}$ in the off-gas forming sulfate aerosols, or by nucleating on entrained ash particles. ${ }^{2,3,17}$ Thermodynamic calculations also suggest that chlorides and hydroxides are the primary vapor carrier species in the reducing gasification fuel gas. ${ }^{3,5,19}$ Because sulfur is essentially present as $\mathrm{H}_{2} \mathrm{~S}$ in the gasification fuel gas, alkali sulfates are not formed in this environment.

Quantification of the alkali vapor in PFBC effluent is a critical issue that has been addressed by many institutions. ${ }^{19-31}$ An Ames on-line, real-time alkali analyzer ${ }^{32,33}$ has been extensively tested at Argonne National Laboratory to measure the alkali ( $\mathrm{Na}$ and $\mathrm{K}$ ) vapor concentration in PFBC effluent. In these measurements, 0.64-cm-dia. (1/4-in.) Type 304 stainless steel tubing was used as a sampling line to extract PFBC effluent for alkali-vapor analysis. In the early phase of calibrating and testing the Ames alkali analyzer with $\mathrm{NaCl}$ vapor, a loss of some of the vapor in the heated $\left(>700^{\circ} \mathrm{C}\right)$ stainless steel sampling line was observed. ${ }^{20}$ To further study this phenomenon, a series of laboratory tests was conducted to expose heated $\left(840-950^{\circ} \mathrm{C}\right.$ ) Type 304 stainless steel tubing to simulated, high-pressure ( $9.2 \mathrm{~atm}$ absolute) PFBC effluent (average composition $3.3 \% \mathrm{O}_{2}, 0.14 \% \mathrm{H}_{2} \mathrm{O}$ vapor, $540 \mathrm{ppmV} \mathrm{SO}_{2}$, alkali vapors, and the balance $\mathrm{N}_{2}$ ) and to examine its high-temperature behavior toward both $\mathrm{NaCl}$ and $\mathrm{KCl}$ vapors. ${ }^{21}$ Figure 5 shows schematically the experimental setup. Typical results from this series of tests are shown in Fig. 6.

Figure 6 clearly shows that, after exposure for $3 \mathrm{~h}$ to a nitrogen gas stream that contained 0.4-2.2 ppmW sodium (as $\mathrm{NaCl}$ vapor) and $0.4-1.5 \mathrm{ppmW}$ potassium (as $\mathrm{KCl}$ vapor), the heated stainless steel gas transport line continuously released both $\mathrm{Na}$ and $\mathrm{K}$ into the alkali-vapor-free 


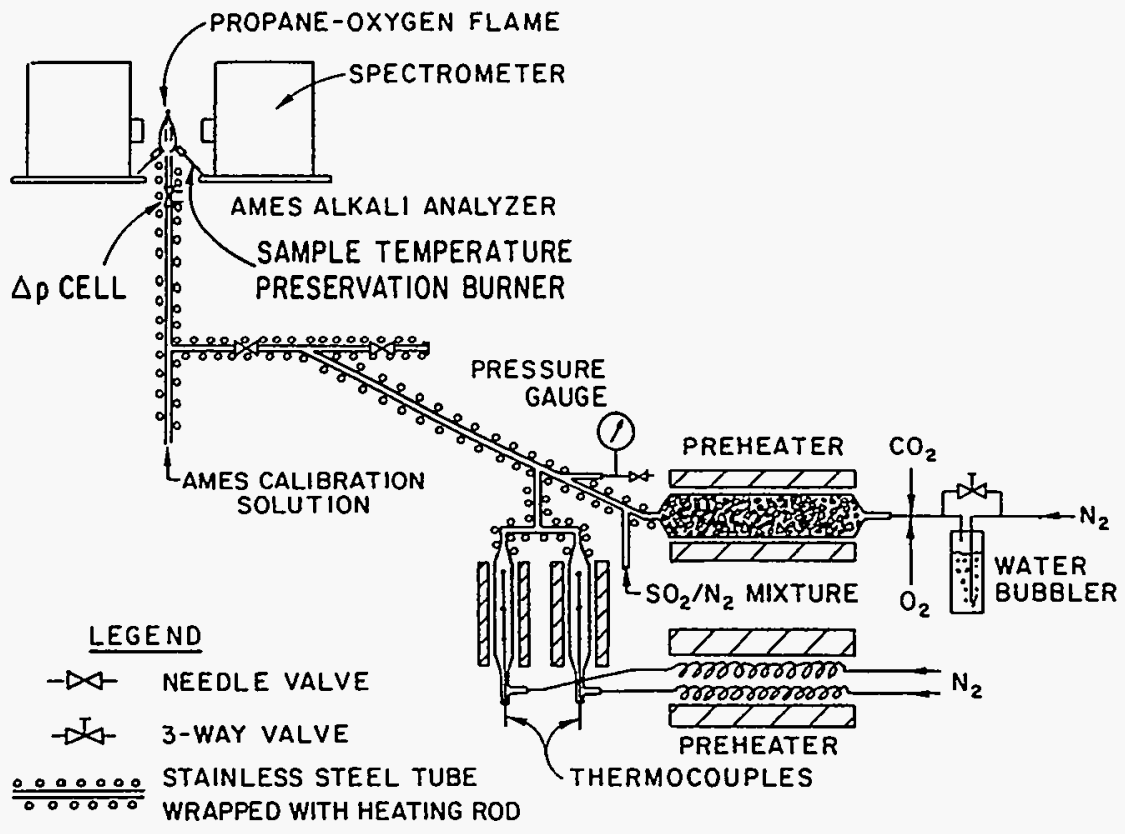

Fig. 5. Schematic of Pressurized NaCl-KCl-Vapor Generation Unit Integrated with Ames On-Line, Real-Time Alkali Analyzer ${ }^{21}$

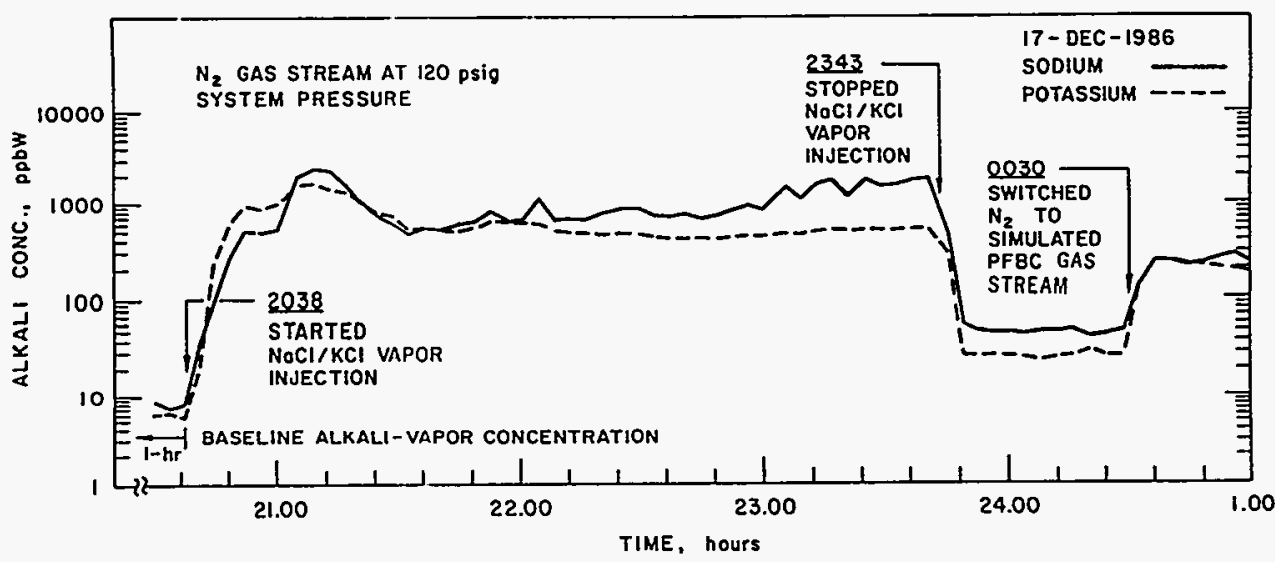

Fig. 6. Measured Sodium and Potassium Concentrations in the Gas Stream for Test of Type 304 Stainless Steel Sampling Line at $840-950^{\circ} \mathrm{C}$ and 9.2 atm Absolute ${ }^{21}$

$\mathrm{N}_{2}$ gas stream. Initial releases ranged from $45-50 \mathrm{ppbW}$ of $\mathrm{Na}$ and $25-30 \mathrm{ppbW}$ of $\mathrm{K}$, and rapidly increased to $220-280 \mathrm{ppbW}$ of $\mathrm{Na}$ and $180-240 \mathrm{ppbW}$ of $\mathrm{K}$ when the alkali-vapor-free simulated off-gas flowed through the line. Similar phenomena were observed when the line was exposed to a simulated $\mathrm{PFBC}$ off-gas containing $\mathrm{NaCl}-\mathrm{KCl}$ vapor. The results of this series of tests verify the previous observation ${ }^{20}$ that heated stainless steel captures $\mathrm{NaCl}$ and $\mathrm{KCl}$ vapors when exposed to a $\mathrm{NaCl}-\mathrm{KCl}$-vapor-bearing gas stream. Also, the captured alkalis are reversibly released to an alkali-vapor-free gas stream. Mechanisms of the alkali vapor capture by and alkali release from the heated Type 304 stainless steel tubing are not known. 
This study, conducted under the auspices of the U.S. Department of Energy, used thermogravimetric analysis (TGA) to experimentally evaluate several candidate materials (iron-, nickel-, and cobalt-based alloys, as well as noble-metal-coated and ceramic-lined alloys) for their capture of alkali vapor under both simulated PFBC (oxidizing) and coal gasification (reducing) environments. The treated materials were analyzed by using various techniques to characterize their alkali adsorption behavior. The objective of this study was to identify non-alkali-adsorbing material(s), if any, that might be suitable for use as process component materials in advanced coal-utilization systems. One specific use would be in the gaseous sampling line for an on-line alkali analyzer. An inert sampling line is needed to ensure the analytical accuracy of the analyzer.

\subsection{EXPERIMENTAL PROCEDURES}

\subsection{Candidate Materials and Their Preparation}

\subsubsection{Candidate Materials}

Table 1 lists the chemical compositions of the nine candidate materials that were tested for their capture of $\mathrm{NaCl}$ vapor in a simulated PFBC off-gas. The $304 \mathrm{SS}$ was included as a base material for comparison. In the second phase of this work, Haynes No. 188 and aluminized $304 \mathrm{SS}$ were also tested for their $\mathrm{NaCl}$-vapor capture in a simulated gasification fuel gas.

Table 1. Chemical Compositions of Candidate Materials, wt $\%$

\begin{tabular}{|c|c|c|c|c|c|c|c|c|c|}
\hline Material & $\mathrm{C}$ & $\mathrm{Cr}$ & $\mathrm{Ni}$ & $\mathrm{Mn}$ & $\mathrm{Si}$ & Mo & W & $\mathrm{Fe}$ & Other \\
\hline 304 SS & 0.08 & 18.3 & 8.10 & 1.5 & 0.27 & 0.27 & - & Bal. $^{\mathrm{a}}$ & - \\
\hline Hastelloy X & 0.10 & 22.0 & Bal. & 0.5 & 0.5 & 9.0 & 0.6 & 18.5 & Co 1.5 \\
\hline Hastelloy C-276 & - & 15.5 & Bal. & 1.0 & - & 16.0 & 3.8 & 5.5 & $\begin{array}{l}\text { Co } 2.5, \\
\text { V } 0.35\end{array}$ \\
\hline Haynes No. 188 & 0.08 & 23.4 & 23.3 & 0.7 & 0.40 & 0.60 & 14.6 & 1.40 & Co 35.7 \\
\hline Pt-Coated 304 SS & 0.08 & 18.3 & 8.10 & 1.5 & 0.27 & 0.27 & - & Bal. & Pt coating \\
\hline Au-Coated 304 SS & 0.08 & 18.3 & 8.10 & 1.5 & 0.27 & 0.27 & - & Bal. & Au coating \\
\hline Ag-Coated 304 SS & 0.08 & 18.3 & 8.10 & 1.5 & 0.27 & 0.27 & - & Bal. & Ag coating \\
\hline Aluminized 304 SS & 0.08 & 18.3 & 8.10 & 1.5 & 0.27 & 0.27 & - & Bal. & $\begin{array}{l}\text { Al diffusion } \\
\text { coating }\end{array}$ \\
\hline $\mathrm{ZrO}_{2}$-Coated $304 \mathrm{SS}$ & 0.08 & 18.3 & 8.10 & 1.5 & 0.27 & 0.27 & - & Bal. & $\begin{array}{l}\mathrm{ZrO}_{2} \text { coat- } \\
\text { ing }\end{array}$ \\
\hline
\end{tabular}

${ }^{\mathrm{a}}$ Bal. = balance 


\subsubsection{Preparation of Specimen Coupons}

Two sets of specimen coupons of each of the candidate materials were prepared. One set was tested in a baseline (containing no $\mathrm{NaCl}$ vapor) simulated $\mathrm{PFBC}$ off-gas and coal gasification fuel gas. The second set was tested in the same simulated gas stream containing about $80 \mathrm{ppmW} \mathrm{NaCl}$ vapor.

Coupons [ $1.27 \mathrm{~cm}(1 / 2$ in.) wide, $2.54 \mathrm{~cm}$ ( 1 in.) long, and $0.127 \mathrm{~cm}(0.05 \mathrm{in})$. thick] were prepared from 304 SS, and from the Hastelloy C-276, Hastelloy X, and Haynes No. 188 alloys. The specimens were finished by polishing with 4000 -grit SiC paper, cleaned in an ultrasonic water bath, and finally rinsed with alcohol. For preparation of the noble-metalcoated specimens, finished 304 SS coupons $(1.27 \times 1.27 \times 0.127 \mathrm{~cm})$ were sputter-deposited with the appropriate metal. The deposited layers were approximately $1 \mu \mathrm{m}$ thick. The sputterdeposited specimens were analyzed using Auger electron spectroscopy (AES). Figure 7 shows the AES spectra and depth profile data for the Pt-deposited specimen, verifying the presence of the Pt layer.

The addition of aluminum to all grades of steel and stainless steel is known to improve their resistance to high-temperature sulfidation, oxidation, and carburization. A commonly known method to achieve this aluminizing is a technique whereby the steel (or stainless steel) material is enclosed in a pack that contains $\mathrm{Fe}-\mathrm{Al}$ powder, inert refractory powder, and a halide activator. The packed material is heated $\left(950-1000^{\circ} \mathrm{C}\right)$ for a sufficient time to allow the elemental aluminum to diffuse into the surface of the steel substrate (average depth of diffusion zone is $150-200 \mu \mathrm{m}$ ). An aluminum-rich alloy (not an aluminum coating) is formed on the surface. Upon further exposure to high temperature in an oxidizing environment, this alloy develops a slow-growing alumina scale that can protect the underlying substrate steel and reduce corrosion.

For this study, a finished 304 SS coupon $(1.27 \times 1.27 \times 0.127 \mathrm{~cm})$ was aluminized by a commercial vendor (Alon Processing, Inc., PA). To monitor the rate of development of alumina scale, the aluminized specimen was pre-oxidized in a muffle furnace at $1000^{\circ} \mathrm{C}$ for 2 and $50 \mathrm{~h}$. Figure 8 shows SEM micrographs of the aluminized 304 SS sample in the as-aluminized condition (a), and after exposure to air at $1000^{\circ} \mathrm{C}$ for 2 and $50 \mathrm{~h}$ (b and c). The figure shows that the specimen develops a continuous $\mathrm{Al}_{2} \mathrm{O}_{3}$ scale after exposure to air at $1000^{\circ} \mathrm{C}$ for $50 \mathrm{~h}$.

The specimens were subsequently analyzed to establish elemental concentrations in the coating-affected regions near the surface. Figure 9 shows the elemental concentration profiles for $\mathrm{Al}, \mathrm{Fe}, \mathrm{Cr}, \mathrm{Ni}$, and $\mathrm{O}$ for aluminized samples in the as-aluminized condition and after exposure to air. The data indicate that the iron concentration varied from $10-40 \mathrm{wt} \%$ in the coated region of the as-aluminized specimen. The effect of pretreatment in air at $1000^{\circ} \mathrm{C}$ was to enhance the formation of alumina scale. The iron concentration was $8-10 \mathrm{wt} \%$ in the 2-h-exposed sample and close to zero in the 50-h-exposed specimen. The alumina scale thickness was $>50 \mu \mathrm{m}$ after $50 \mathrm{~h}$ exposure at $1000^{\circ} \mathrm{C}$ in air. Based on these results, all aluminized $304 \mathrm{SS}$ coupon specimens were pre-oxidized at $1000^{\circ} \mathrm{C}$ in air for $50 \mathrm{~h}$ before they were subjected to further testing. 

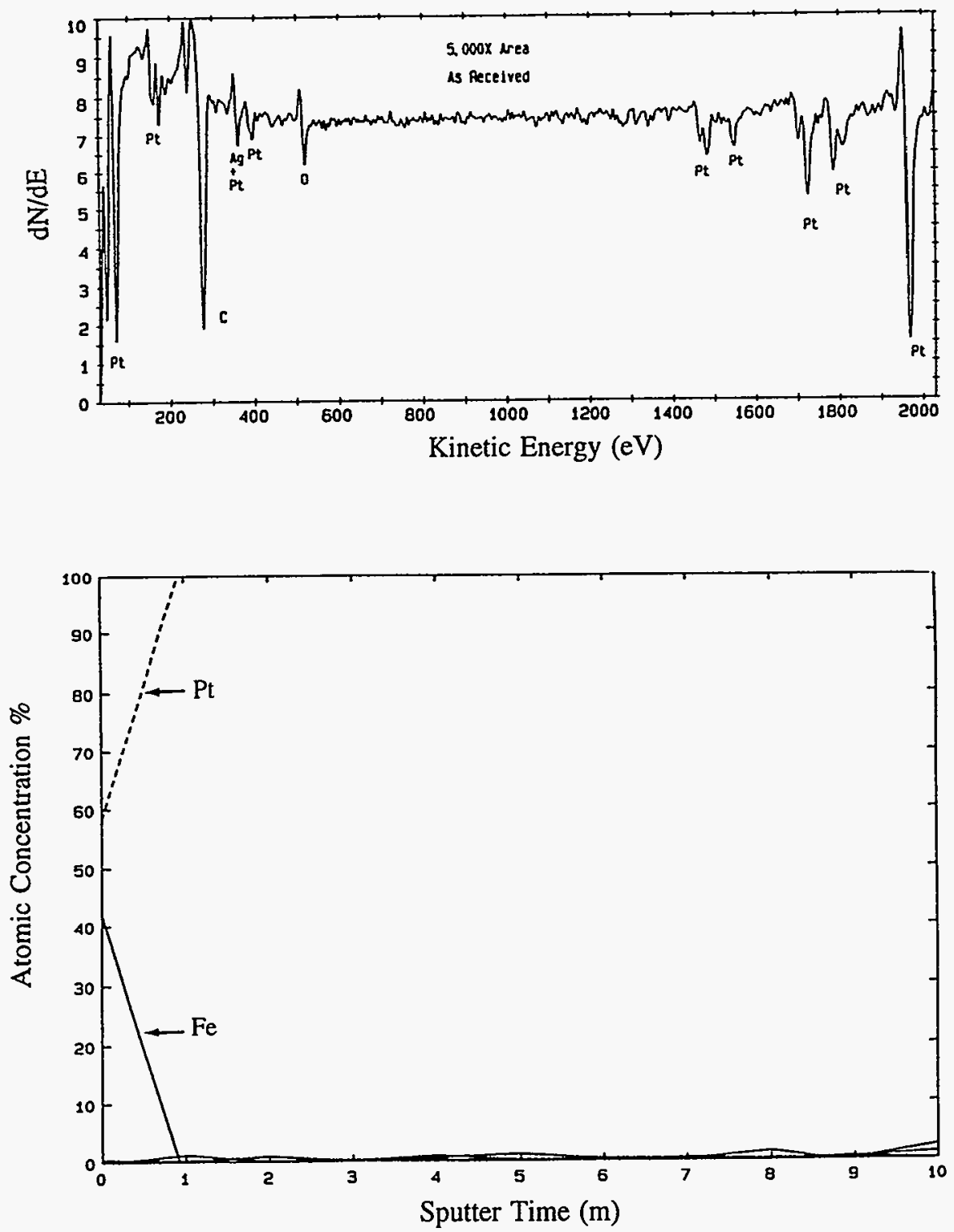

Fig. 7. Auger Electron Spectroscopy (Top) and Depth Profile Analysis (Bottom) for Pt-Coated 304 SS Specimen

The $\mathrm{ZrO}_{2}$-coated $304 \mathrm{SS}$ coupon specimen $(1.27 \times 1.27 \times 0.127 \mathrm{~cm})$ was prepared by depositing (1) a layer of bond coat of (Ni, Co) $\mathrm{Cr} \mathrm{Al} \mathrm{Y} \mathrm{and} \mathrm{(2)} \mathrm{an} \mathrm{external} \mathrm{ceramic} \mathrm{coating} \mathrm{of}$ $\mathrm{ZrO}_{2}$ by use of a thermal spray process. Due to the nature of the coating process, only one side of the coupon was coated with $\mathrm{ZrO}_{2}$. The bond layer and the $\mathrm{ZrO}_{2}$ coating were $\sim 100$ and $\sim 500 \mu \mathrm{m}$ thick, respectively.

\subsection{Test Equipment and Procedures}

Figure 10 shows schematically the thermogravimetric analyzer (TGA) setup for experimental testing of the candidate materials (Table 1) in a simulated PFBC off-gas. A coupon was suspended in the TGA and heated to a controlled temperature by a 3-zone tubular furnace. The 

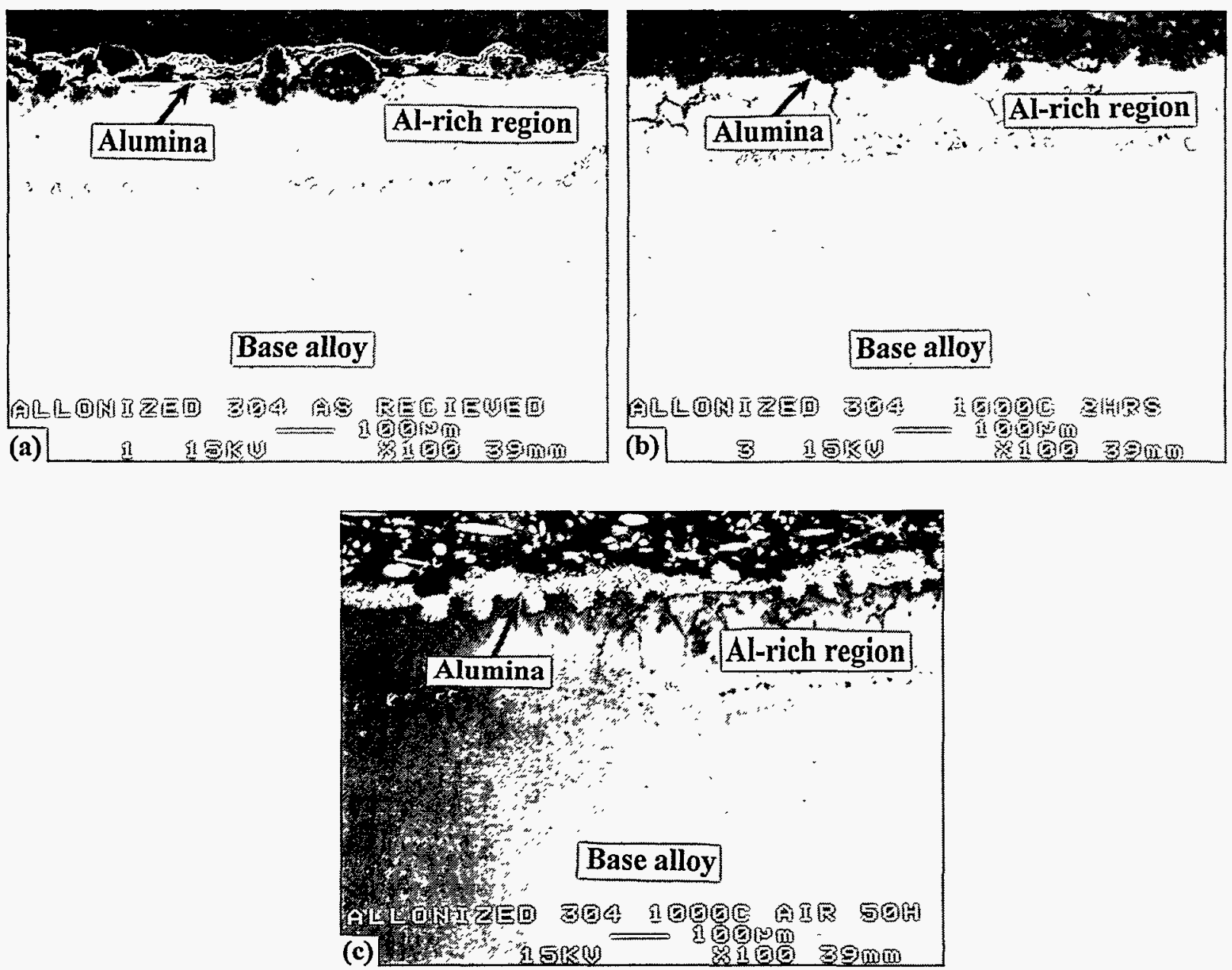

Fig. 8. SEM Micrographs of Cross Sections of Aluminized 304 SS in the (a) as-Aluminized Condition, and after Exposure to Air at $1000^{\circ} \mathrm{C}$ for (b) 2 and (c) $50 \mathrm{~h}$

$\mathrm{NaCl}$ vapor generated from a $\mathrm{NaCl}$ bed was carried upward to the coupon by preheated simulated PFBC off-gas that was introduced into the TGA from the bottom of the $\mathrm{Al}_{2} \mathrm{O}_{3}$ reactor tube (2.54-cm ID). A packed bed of $\mathrm{Al}_{2} \mathrm{O}_{3}$ chips served as a heat-transfer medium. To prevent vapor condensation on the platinum wire on which the coupon specimen was suspended, a downflow of nitrogen purge gas was introduced into the TGA, as shown in Fig. 10. Temperatures of both the specimen and the $\mathrm{NaCl}$ bed were monitored by thermocouples. Table 2 shows the test conditions. The coupons were exposed to the simulated PFBC off-gas at $870-875^{\circ} \mathrm{C}$ and atmospheric pressure for $100 \mathrm{~h}$. The weight change of the sample was continuously recorded for the duration of the test.

Baseline testing was conducted in the TGA in the absence of an $\mathrm{NaCl}$ bed. All baseline tests were completed first to prevent contamination of the setup by $\mathrm{NaCl}$ vapor. For tests with $\mathrm{NaCl}$ vapor, the coupon was maintained at a much higher temperature $\left(870-875^{\circ} \mathrm{C}\right)$ than the $\mathrm{NaCl}$ bed $\left(715^{\circ} \mathrm{C}\right)$ to prevent $\mathrm{NaCl}$ vapor from condensing on the specimen. In the initial tests 

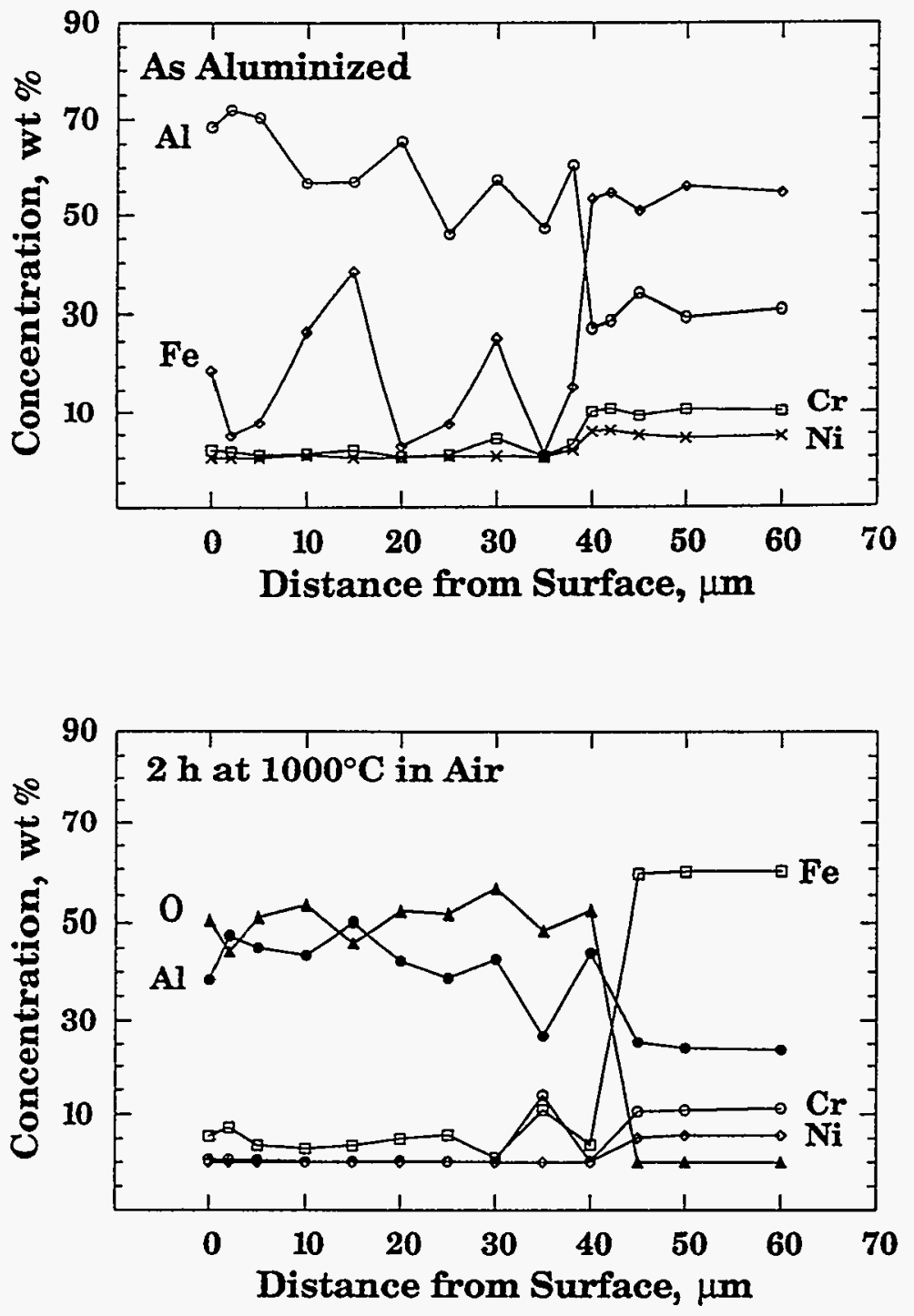

Fig. 9.

Elemental Concertration Profiles for $\mathrm{Al}, \mathrm{Cr}, \mathrm{Fe}, \mathrm{Ni}$, and $\mathrm{O}$ in the Near-Surface Regions of Aluminized 304 SS:

(Top) as-Aluminized

Condition, (Middle) after Exposure in Air at $1000^{\circ} \mathrm{C}$ for $2 \mathrm{~h}$, (Bottom) after Exposure for $50 \mathrm{~h}$

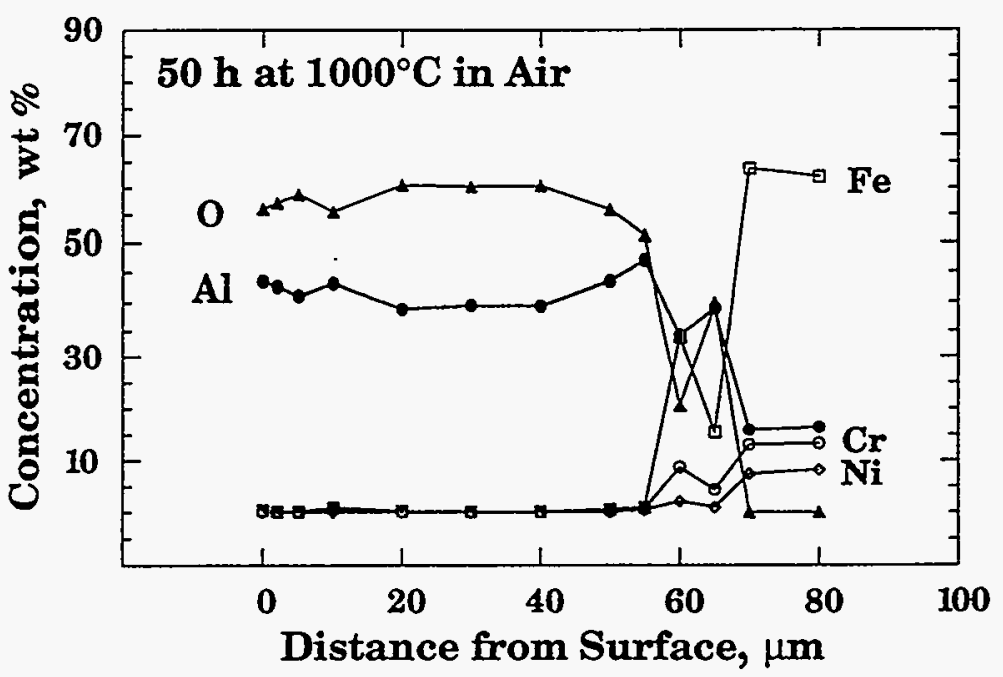




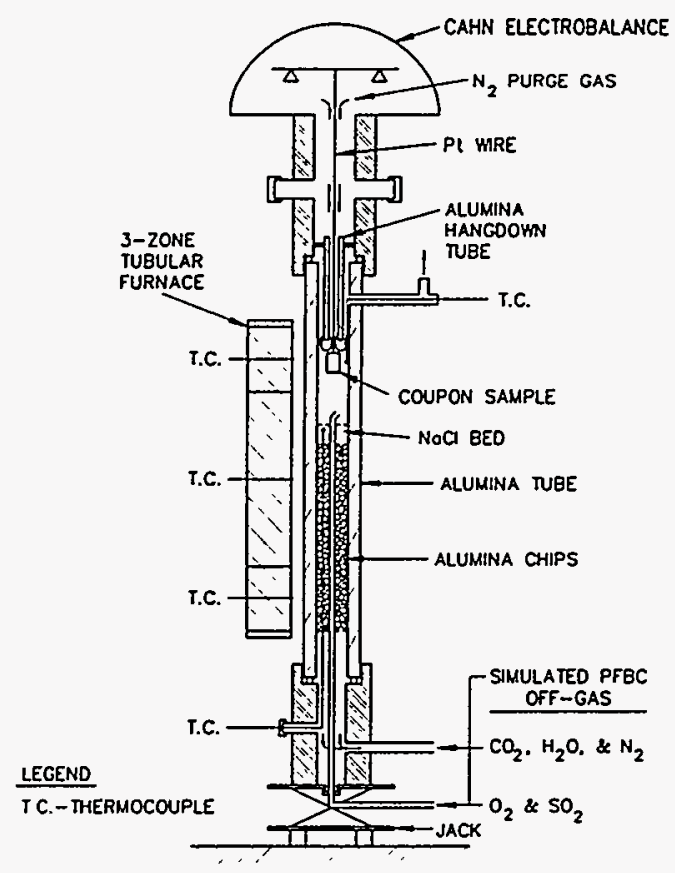

Fig. 10.

TGA Setup for Studying Alkali-Vapor Capture by Metallic Materials

Table 2. Experimental Conditions for Atmospheric TGA Tests of Candidate Materials in Simulated PFBC Environment

\begin{tabular}{||c|c|c||}
\hline Coupon Temperature & \multicolumn{2}{|c|}{$870-875^{\circ} \mathrm{C}$} \\
\hline Total Flow Rate to Reactor & \multicolumn{2}{|c|}{$500 \mathrm{~mL} / \mathrm{min}$} \\
\hline Test Duration & \multicolumn{2}{|c|}{$100 \mathrm{~h}$} \\
\hline Simulated PFBC Off-Gas Compositions & Component & Concentration \\
\hline & $\mathrm{O}_{2}$ & 3.1 vol\% \\
& $\mathrm{CO}_{2}$ & $14.7 \mathrm{vol} \%$ \\
& $\mathrm{H}_{2} \mathrm{O} \mathrm{Vapor}$ & $2.0 \mathrm{vol} \%$ \\
& $\mathrm{SO}_{2}$ & $880 \mathrm{ppmV}$ \\
& $\mathrm{NaCl} \mathrm{Vapor}$ & 0 and $80 \mathrm{ppmW}$ \\
& $\mathrm{N}_{2}$ & Balance \\
\hline
\end{tabular}

with $\mathrm{NaCl}$ vapor, the coupon and the $\mathrm{NaCl}$ bed were cooled simultaneously (by shutting off the power to the tubular furnace), which is referred to as "initial test-end cooling." There was a concern that, during the cooling period, the residual $\mathrm{NaCl}$ vapor in the reactor tube might either condense on the specimen or react with $\mathrm{SO}_{2}$ to form $\mathrm{Na}_{2} \mathrm{SO}_{4}$, which might subsequently condense on the specimen. Thus, the test-end cooling procedure was modified as follows: the specimen was kept at the test temperature while the $\mathrm{NaCl}$ bed was cooling and the simulated 
PFBC off-gas was shut off; after the $\mathrm{NaCl}$ bed had cooled to $<400^{\circ} \mathrm{C}$, the coupon itself was cooled. This modified procedure is referred to as "modified test-end cooling."

For tests in the simulated coal gasification fuel gas, the TGA setup was slightly modified to accept the simulated fuel gas (i.e., $20 \% \mathrm{H}_{2}, 19 \% \mathrm{CO}, 5 \% \mathrm{CH}_{4}, 0.2 \% \mathrm{H}_{2} \mathrm{~S}, 12 \% \mathrm{CO}_{2}, 2 \% \mathrm{H}_{2} \mathrm{O}$ vapor, 0 and $80 \mathrm{ppmW} \mathrm{NaCl}$ vapor, and the balance $\mathrm{N}_{2}$ ). The combustible gas stream (a mixture of $\mathrm{H}_{2}, \mathrm{CO}, \mathrm{CH}_{4}, \mathrm{H}_{2} \mathrm{~S}$, and $\mathrm{N}_{2}$ ) was introduced into the reactor through the central $\mathrm{Al}_{2} \mathrm{O}_{3}$ tubing. Because of the presence of combustible gases in the simulated fuel gas stream, a comprehensive safety review of the setup and test procedures was conducted to ensure the safe operation of the system.

At the end of each test, the after-test coupon specimen was analyzed by SEM/EDX. Near-surface regions of selected coupons were further analyzed by AES, a technique that can be used to determine the elemental composition of the outer monolayer of an electrically conductive solid without the use of standards. The average detectability limit is $\sim 0.1$ at.\%. The technique involves striking the sample with an electron beam and measuring the energy of the Auger electrons that the sample emits. These Auger electrons have an escape depth of 5-50 $\AA$. Analysis of coupons was also conducted in a AES system equipped with an ion gun that was used to fire high voltage argon ions into the sample. In time these ions erode the sample. By monitoring the signal from the Auger electrons with respect to sputtering time it is possible to generate a "sputter depth profile" which determines the concentration of the elements as a function of sample depth.

\subsection{RESULTS AND DISCUSSION}

\subsection{Tests in Baseline Simulated PFBC Off-Gas}

Table 3 shows the total weight change of test specimens after exposure to the baseline simulated PFBC off-gas (Table 2) at $870-875^{\circ} \mathrm{C}$ for $100 \mathrm{~h}$. Figure 11 shows SEM micrographs of the test specimens. Prior to testing, the finished coupons of 304 SS, Hastelloy X, Hastelloy C-276, Haynes No. 188, Pt-coated 304 SS, Au-coated 304 SS, and Ag-coated 304 SS were shiny; however, during the exposure they all formed black scales. These scales were basically oxides of $\mathrm{Cr}, \mathrm{Fe}$, and/or $\mathrm{Ni}$, which caused the weight gain of the tested coupon specimens, as shown in Table 3. The weight loss of the Ag-coated 304 SS was probably due to the spalling off of the scale during the test.

The scale thicknesses for the 304 SS, Hastelloy X, and Haynes No. 188 were fairly uniform, in the range of 2-3 $\mu \mathrm{m}$. The scale on the Hastelloy C-276 was 8-10 $\mu \mathrm{m}$ thick and exhibited a ragged surface morphology with a number of cracks and voids. Results of the EDX elemental analyses of the base metal and scale of the exposed specimens are shown in Figs. 12 and 13. The scale was predominantly $\mathrm{Cr}_{2} \mathrm{O}_{3}$ for $304 \mathrm{SS}$, Hastelloy X, and Haynes No. 188 whereas the oxide scale on Hastelloy $\mathrm{C}-276$ contained $\mathrm{Cr}$, Fe, and Ni. The lower concentration of chromium (15.5 wt\%) in Hastelloy C-276 is not sufficient to form pure chromia scale at the temperature range of $870-875^{\circ} \mathrm{C}$. No sulfur was detected in the scale on the alloy substrate. 
Table 3. Total Weight Change of Candidate Materials Tested in Baseline Simulated PFBC Off-Gas (No NaCl Vapor)

\begin{tabular}{||c|c|c|c|}
\hline Material & $\begin{array}{c}\text { Specimen } \\
\text { Dimensions, } \\
\mathrm{cm}\end{array}$ & $\begin{array}{c}\text { Initial } \\
\text { Specimen Wt, } \\
\mathrm{g}\end{array}$ & $\begin{array}{c}\text { Total Wt } \\
\text { Change, } \\
\mathrm{mg} / \mathrm{cm}^{2}\end{array}$ \\
\hline 304 SS & $2.54 \times 1.27 \times 0.127$ & 2.9936 & +0.43 \\
\hline Hastelloy X & $2.54 \times 1.27 \times 0.127$ & 2.7802 & +0.42 \\
\hline Hastelloy C-276 & $2.54 \times 1.27 \times 0.127$ & 3.5294 & +0.36 \\
\hline Haynes No. 188 & $2.54 \times 1.27 \times 0.127$ & 3.1149 & +0.19 \\
\hline Pt-coated 304 SS & $1.27 \times 1.27 \times 0.127$ & 1.5963 & +0.44 \\
\hline Au-coated 304 SS & $1.27 \times 1.27 \times 0.127$ & 1.5503 & +0.44 \\
\hline Ag-coated 304 SS & $1.27 \times 1.27 \times 0.127$ & 1.5513 & -1.42 \\
\hline Aluminized 304 SS & $1.27 \times 1.27 \times 0.127$ & 1.8702 & +1.40 \\
\hline
\end{tabular}

${ }^{\mathrm{a}} \mathrm{L} \times \mathrm{W} \times \mathrm{T}$.

${ }^{b}$ Weight change after 100-h exposure.

${ }^{\circ}$ The specimen had been preheated in air at $1000^{\circ} \mathrm{C}$ for $50 \mathrm{~h}$.

For Pt-, Au-, and Ag-coated 304 SS, the sputter deposit of the noble metals did not prevent outward diffusion of substrate elements ( $\mathrm{Cr}$ and/or $\mathrm{Fe}$ ) and subsequent oxidation of these elements, but the oxide morphology was very different from that obtained without the coating. The oxide thicknesses were in the same range $(2-3 \mu \mathrm{m})$, however, the oxides on the uncoated sample exhibited ragged morphology while those on the coated specimens were smooth. As shown in Fig. 13, the oxide composition in the Pt-coated 304 SS coupon specimen was almost pure $\mathrm{Cr}_{2} \mathrm{O}_{3}$, that in the Au-coated sample was $(\mathrm{Cr}, \mathrm{Fe})$ oxide, and that in the Ag-coated sample was iron oxide. Some of this iron oxide probably spalled off during the test, resulting in the weight loss shown in Table 3. No sulfur was detected in any of the samples after exposure to the $\mathrm{SO}_{2}$-containing PFBC off-gas.

As a result of the aluminizing process, the pretreated aluminized 304 SS coupon exhibited a rough and light-brownish surface. As shown in Table 3 , this specimen also gained weight after exposure to the baseline simulated PFBC off-gas, suggesting the continuing growth of $\mathrm{Al}_{2} \mathrm{O}_{3}$ scale during the exposure $(100 \mathrm{~h})$. The SEM micrographs for the cross-section of the exposed specimen (Figure 11) show that the alumina scale (developed during the pretreatment in air at $1000^{\circ} \mathrm{C}$ for $50 \mathrm{~h}$ ) was continuous and intact after exposure. No sulfur was detected in the scale or the alloy substrate. Figure 14 shows the elemental concentration profiles across the scale and substrate alloy (top figure) and in the near surface regions (bottom figure) of the exposed specimen. It is evident that the alumina scale remained intact to a depth of $40 \mu \mathrm{m}$ during the 100-h exposure. 

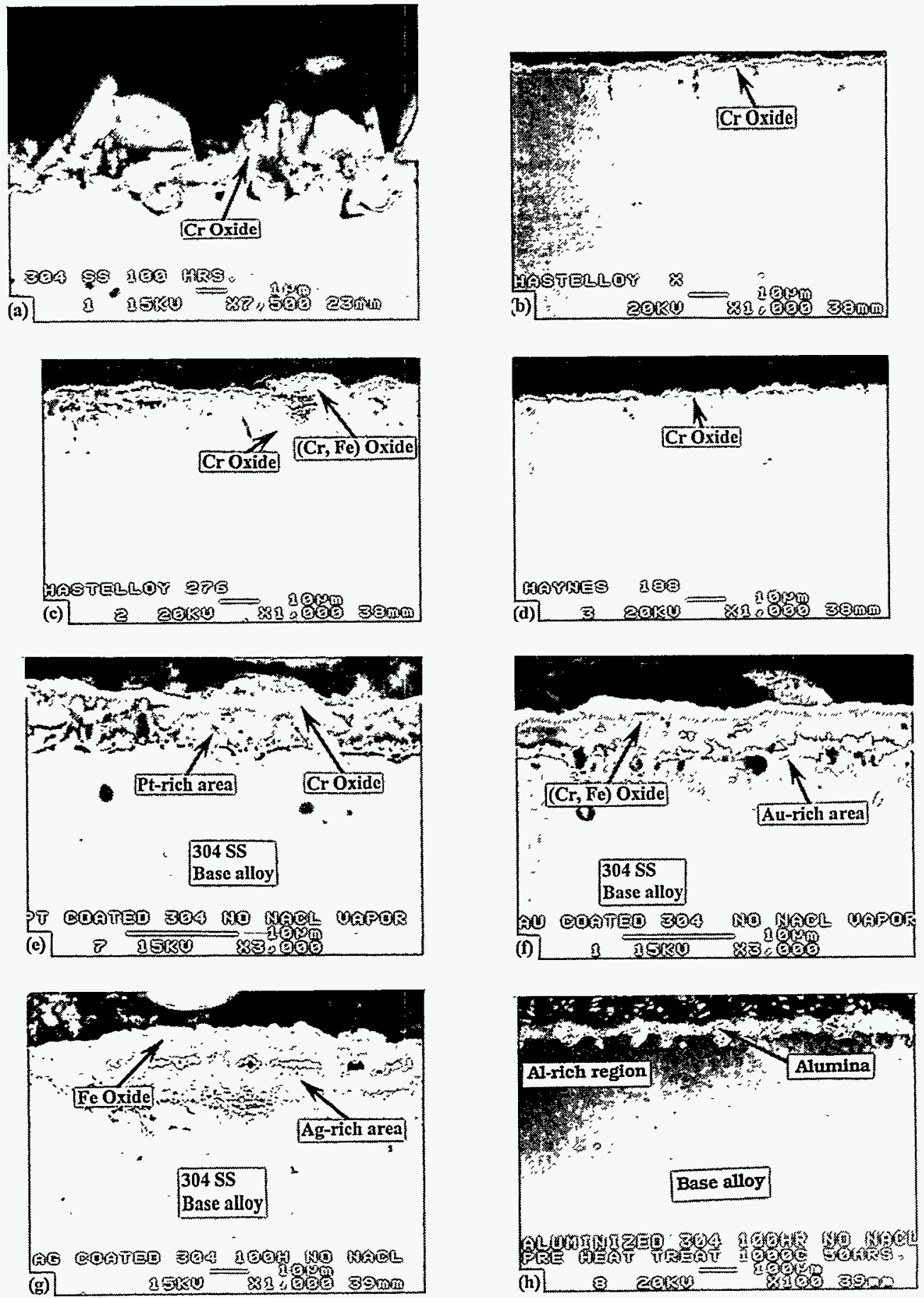

Fig. 11. SEM Micrographs of Cross Sections of Test Specimens after Exposure to Baseline Simulated PFBC Off-Gas (No NaCl Vapor): (a) 304 SS, (b) Hastelloy X, (c) Hastelloy C-276, (d) Haynes No. 188, (e) Pt-Coated 304 SS, (f) Au-Coated 304 SS, (g) Ag-Coated 304 SS, and (h) Pretreated $\left(1000^{\circ} \mathrm{C}\right.$ for $50 \mathrm{~h}$ in air) Aluminized $304 \mathrm{SS}$ 

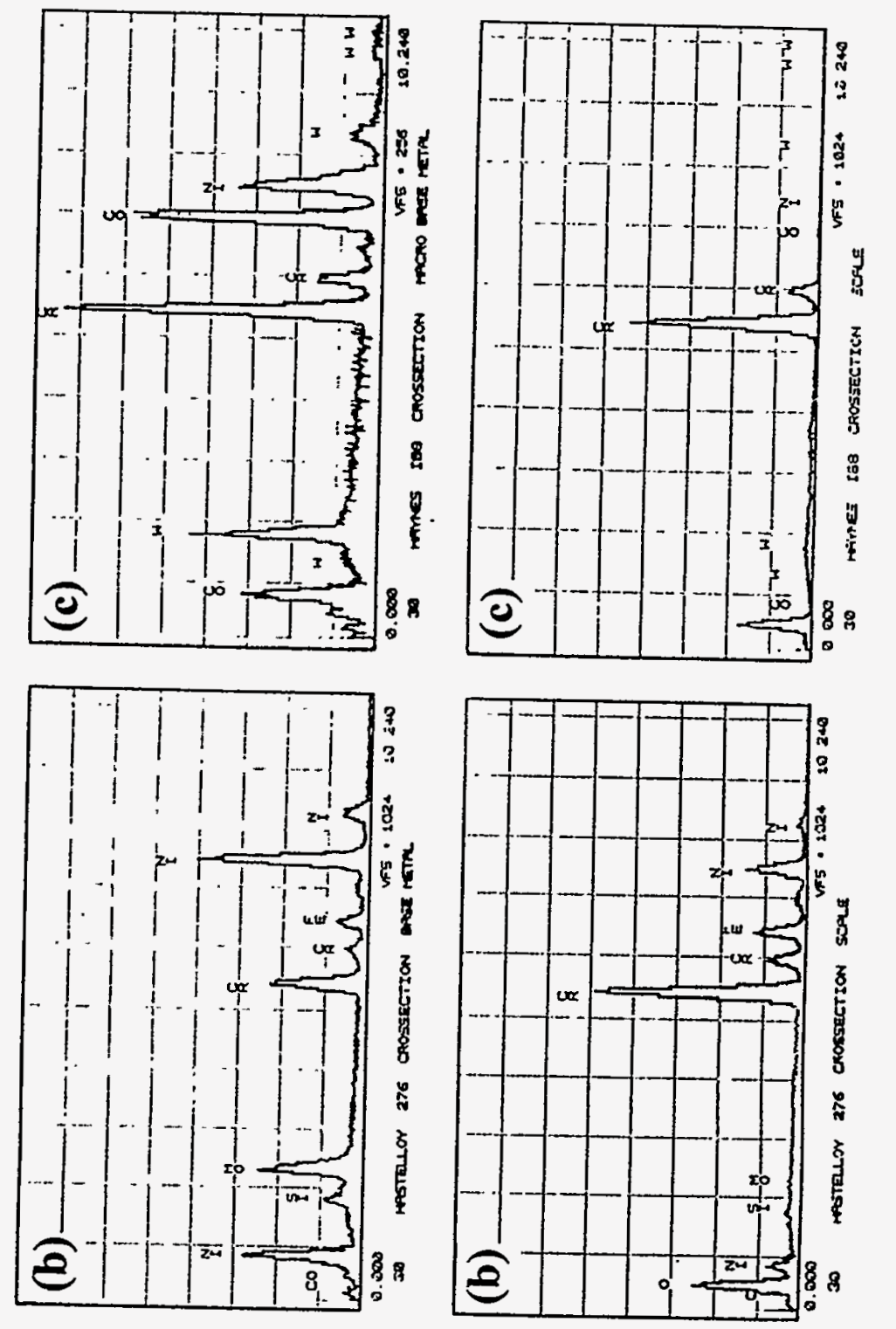

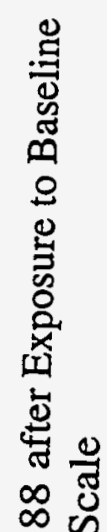
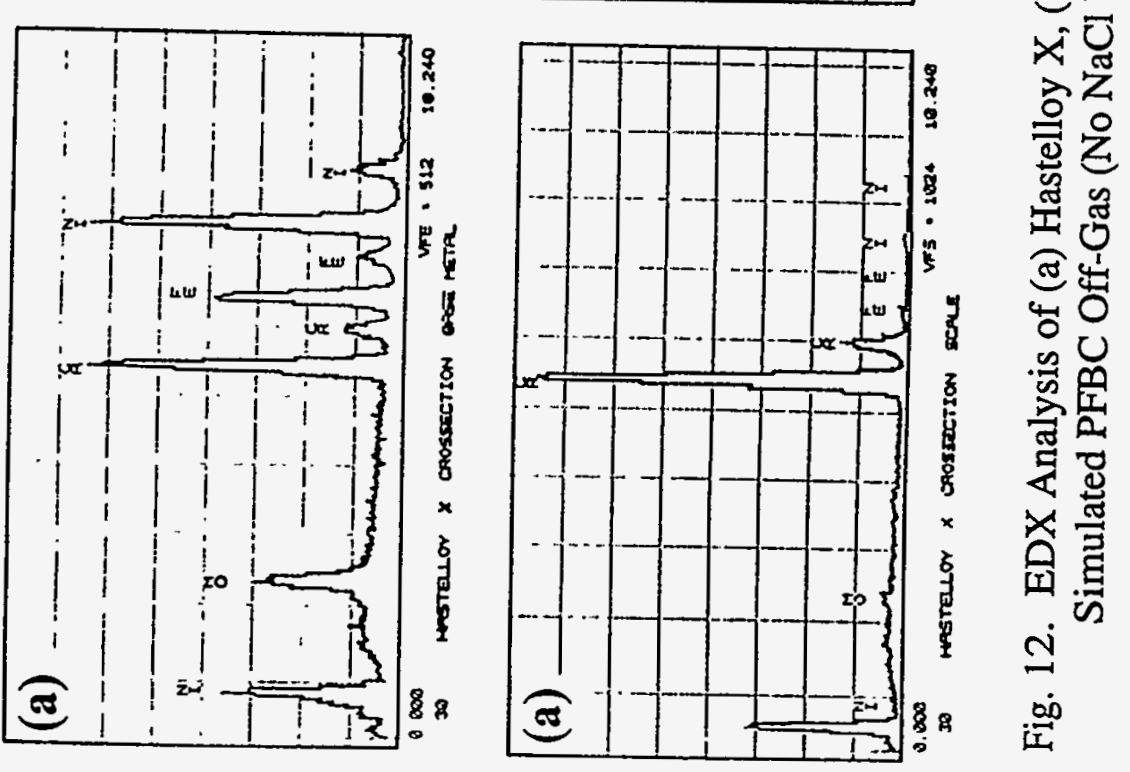

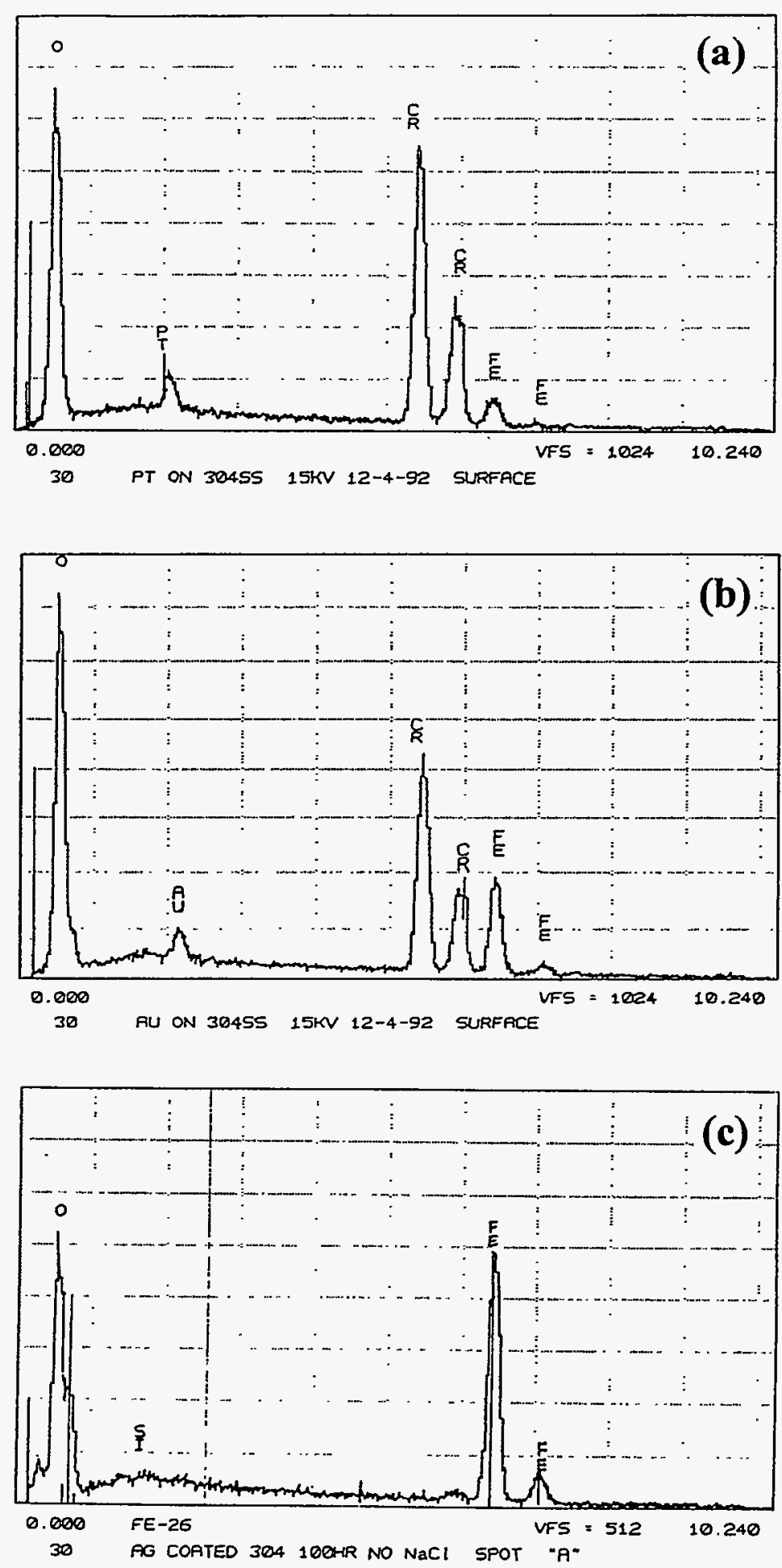

Fig. 13. EDX Analysis of Scales of (a) Pt-Coated 304 SS, (b) Au-Coated 304 SS, and (c) Ag-Coated $304 \mathrm{SS}$ after Exposure to Baseline Simulated PFBC Off-Gas (No $\mathrm{NaCl}$ Vapor) 

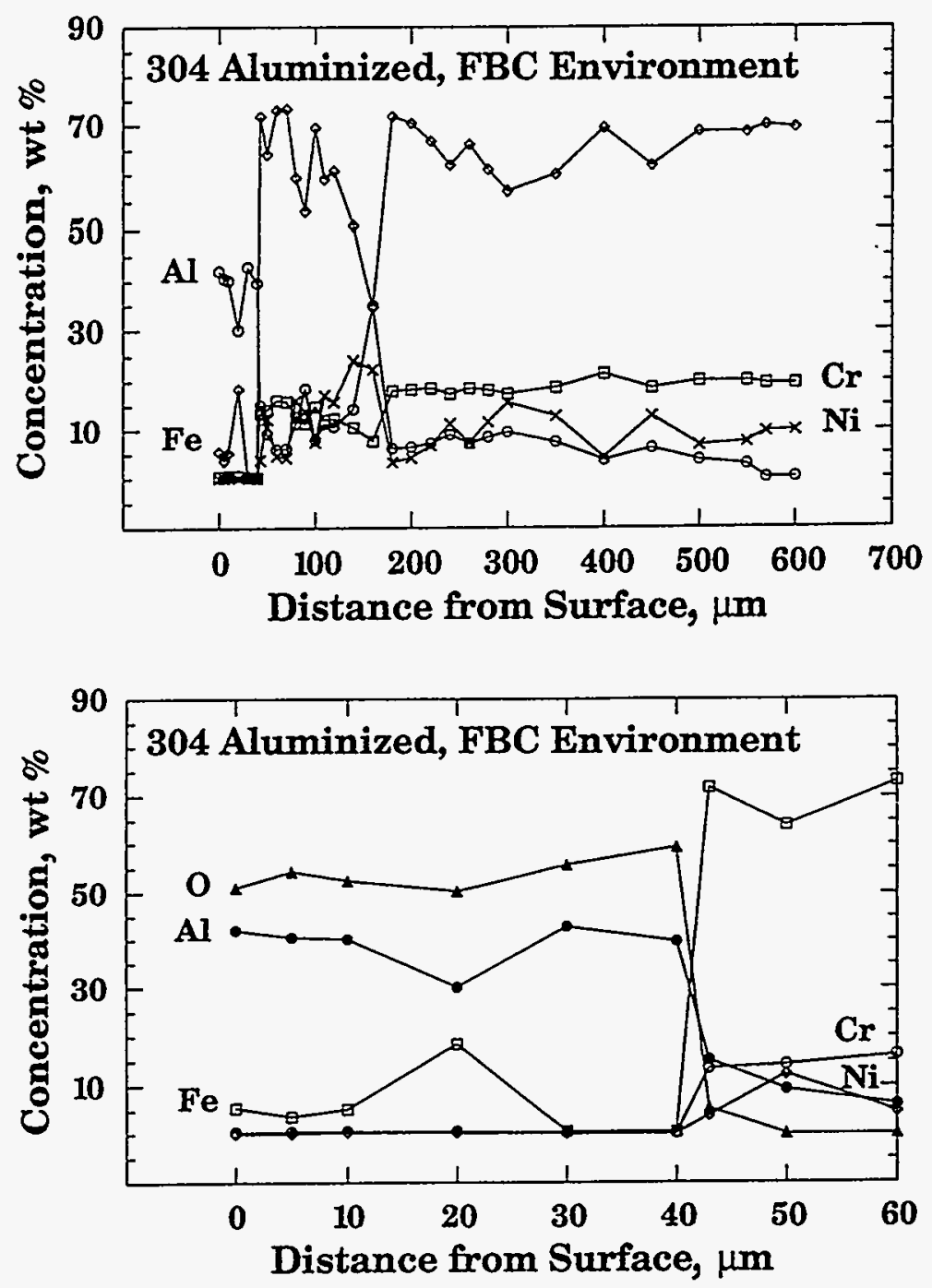

Fig. 14. Elemental Concentration Profiles for $\mathrm{Al}, \mathrm{Cr}$, $\mathrm{Fe}, \mathrm{Ni}$, and $\mathrm{O}$ in the Pretreated Aluminized 304 SS after Exposure to Baseline Simulated PFBC Off-Gas (No $\mathrm{NaCl}$ Vapor):

(Top) Across the Scale and Substrate Alloy and (Bottom) Near-Surface Regions

\subsection{Tests in Simulated PFBC Off-Gas Containing NaCl Vapor}

Table 4 summarizes the total weight gain of all the coupons after exposure to the simulated PFBC off-gas (Table 2) containing $\sim 80 \mathrm{ppmW} \mathrm{NaCl}$ vapor. As in the baseline tests, the coupons of 304 SS, Hastelloy X, Hastelloy C-276, Haynes No. 188, Pt-coated 304 SS, Au-coated 304 SS, and Ag-coated 304 SS were initially shiny, but became black during exposure, suggesting the formation of oxide scales that resulted in the weight gain. The weight gains were significantly greater than those observed in the baseline tests (Table 3). The black scales of the 304 SS, Hastelloy X, Haynes No. 188, Pt-coated 304 SS, and Au-coated 304 SS 
Table 4. Total Weight Change of Candidate Materials Tested in Simulated PFBC Off-Gas Containing $\mathrm{NaCl}$ Vapor

\begin{tabular}{|c|c|c|}
\hline Material & Specimen Dimensions, ${ }^{\mathrm{a}} \mathrm{cm}$ & Total Wt Change, $^{\mathrm{b}} \mathrm{mg} / \mathrm{cm}^{2}$ \\
\hline 304 SS & $2.54 \times 1.27 \times 0.127$ & +1.31 \\
\hline Hastelloy X & $2.54 \times 1.27 \times 0.127$ & +1.68 \\
\hline Hastelloy C-276 & $2.54 \times 1.27 \times 0.127$ & $>+8.69^{\mathrm{c}}$ \\
\hline Haynes No. 188 & $2.54 \times 1.27 \times 0.127$ & +1.70 \\
\hline Pt-Coated 304 SS & $1.27 \times 1.27 \times 0.127$ & +2.97 \\
\hline Au-Coated 304 SS & $1.27 \times 1.27 \times 0.127$ & +1.27 \\
\hline Ag-Coated 304 SS & $1.27 \times 1.27 \times 0.127$ & $>+3.72^{\mathrm{c}}$ \\
\hline Aluminized 304 SS & $1.27 \times 1.27 \times 0.127$ & +3.36 \\
\hline $\mathrm{ZrO}_{2}$-Coated 304 SS & $1.27 \times 1.27 \times 0.127$ & N.D. \\
\hline
\end{tabular}

${ }^{\mathrm{a}} \mathrm{L} \times \mathrm{W} \times \mathrm{T}$.

${ }^{b}$ Weight change after 100 -h exposure.

' The after-test specimen was badly corroded. Some scales may have peeled off.

${ }^{d}$ The specimen had been preheated in air at $1000^{\circ} \mathrm{C}$ for $50 \mathrm{~h}$.

${ }^{\mathrm{e}}$ Not determined.

specimens appeared visually firm and smooth. By contrast, the Hastelloy C-276 and Ag-coated 304 SS specimens became severely corroded with the black scales peeling off the specimens. Their abnormal weight gain shown in Table 4 reflects this observation. A repeat test with the Hastelloy C-276 coupon under the same experimental conditions for $25 \mathrm{~h}$ showed similar results. The rough, light-brownish surface of the pre-oxidized aluminized 304 SS coupon specimen, which is a result of the aluminizing process, appeared intact (no color change) after the test. However, the weight gain of this aluminized 304 SS was also significantly greater than that obtained in the baseline condition (no $\mathrm{NaCl}$ vapor). Due to the nature of the coating process, the $\mathrm{ZrO}_{2}$-coated $304 \mathrm{SS}$ coupon specimen was coated only on one side; therefore, a meaningful weight gain could not be obtained.

The exposed coupons were analyzed by both SEM and AES. Figures 15, 16, 17, and 18 show the SEM micrographs and Tables 5 and 6 summarize the AES data for all tested specimens.

\subsection{1 $\underline{304 \mathrm{SS}}$}

Earlier laboratory studies ${ }^{20,21}$ indicated that the heated Type 304 stainless steel tube (used as a sampling line in the on-line Ames alkali analyzer) captures $\mathrm{NaCl}$ and $\mathrm{KCl}$ vapors when exposed to $\mathrm{NaCl}-\mathrm{KCl}$-vapor-bearing simulated $\mathrm{PFBC}$ off-gas. The $304 \mathrm{SS}$ was included in this study as a base material for comparison. Figure 15 shows SEM micrographs of surfaces and cross-sections of two 304 SS coupons (Specimen 304 SS-1 and Specimen 304 SS-2). Specimen 304 SS-1 (Figs. 15a and 15b) underwent a 100-h test completed by initial test-end cooling; and Specimen 304 SS-2 (Figs. 15c and 15d) underwent a duplicate 90 -h test with the modified testend cooling procedure. 

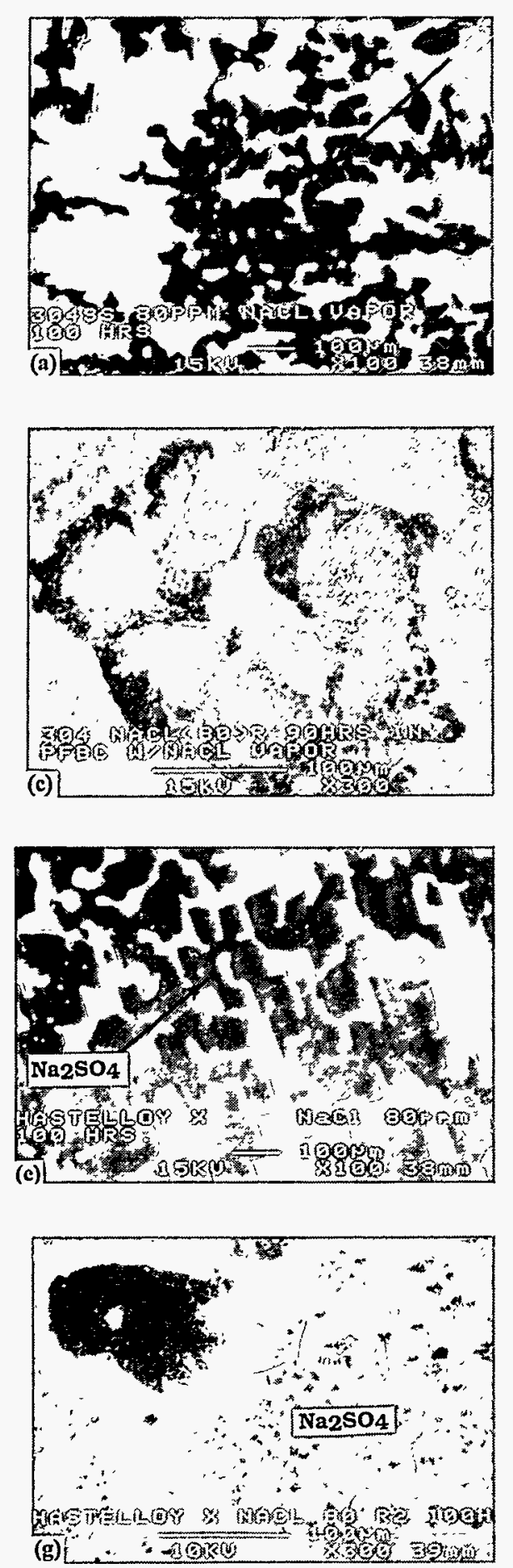
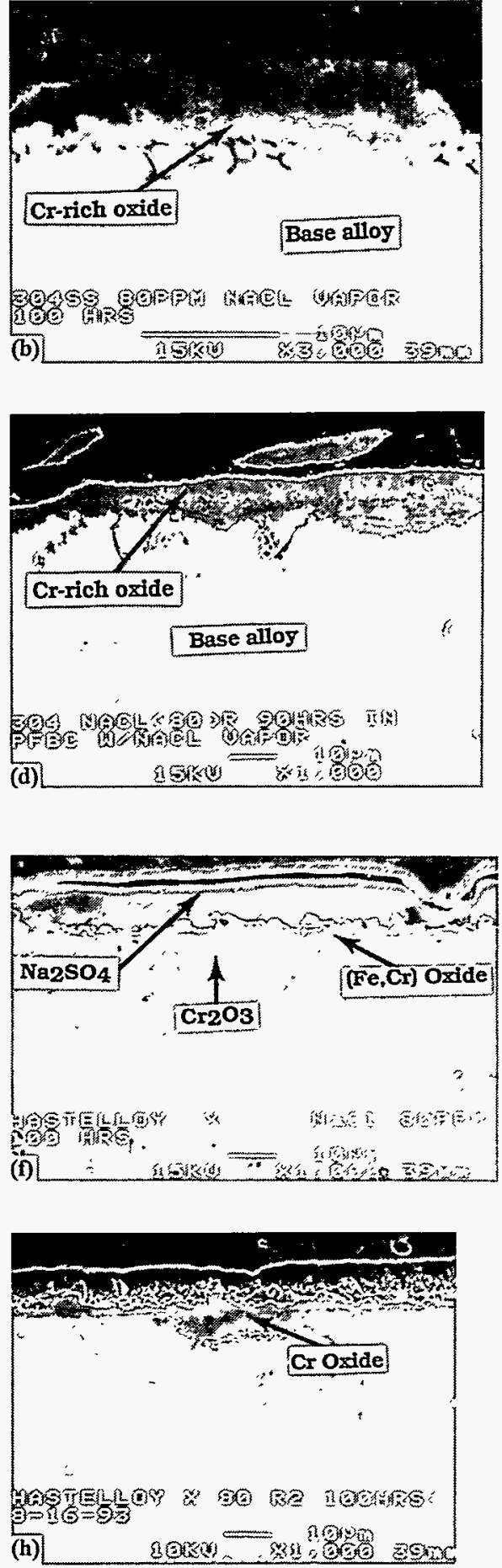

Fig. 15. SEM Micrographs of Surfaces (Left Column) and Cross Sections (Right Column) of 304 SS (a, b, c, and d) and Hastelloy X (e, f, g, and h) after Exposure to Simulated PFBC Off-Gas Containing $\mathrm{NaCl}$ Vapor

(a), (b), (e), and (f): 100-h Test w/ Initial Test-End Cooling

(c) and (d): 90-h Test w/ Modified Test-End Cooling

(g) and (h): 100-h Test w/ Modified Test-End Cooling 


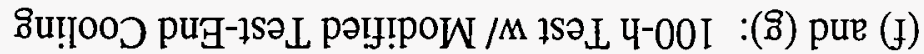

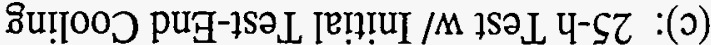

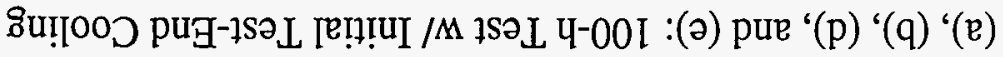

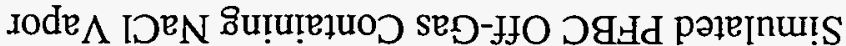

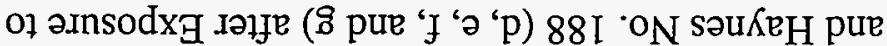

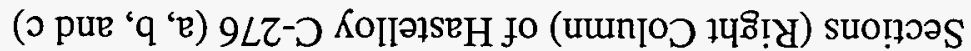

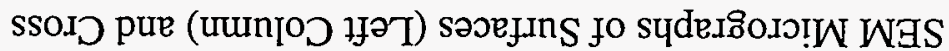
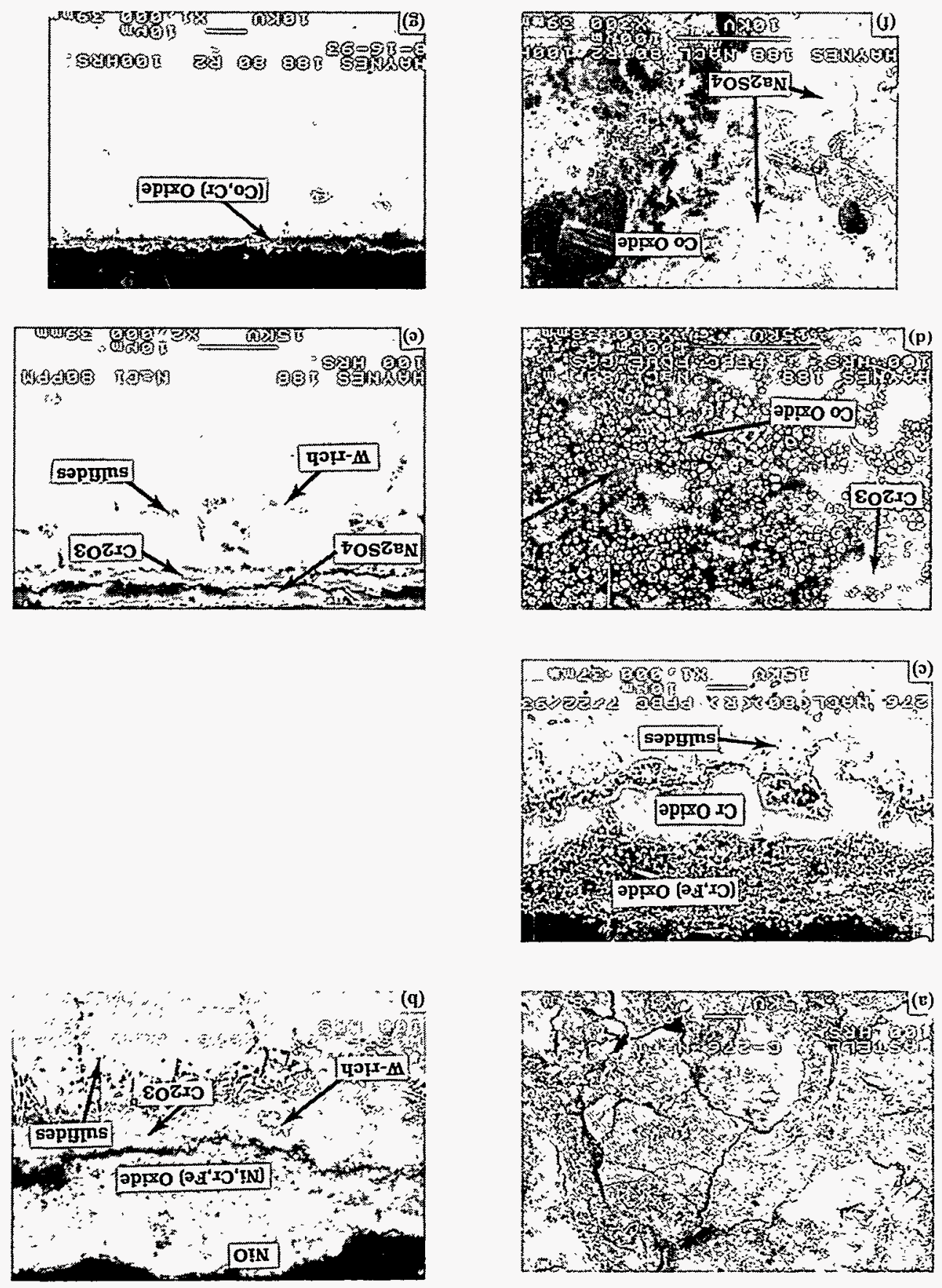

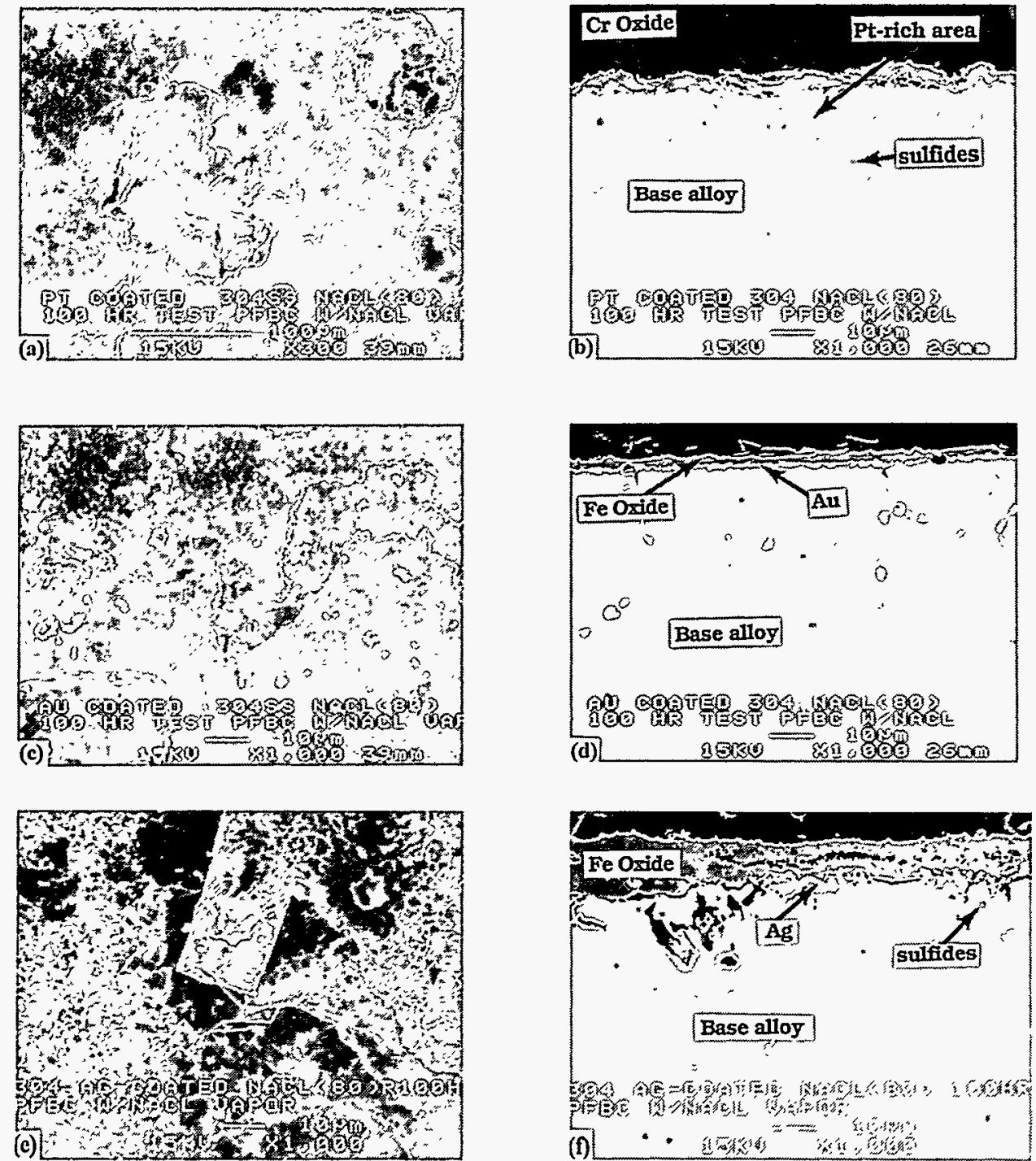

Fig. 17. SEM Micrographs of Surfaces (Left Column) and Cross Sections (Right Column) of Pt-Coated ( $\mathrm{a}$ and b), Au-Coated (c and d), and Ag-Coated (e and f) 304 SS after Exposure to Simulated PFBC Off-Gas Containing $\mathrm{NaCl}$ Vapor (a), (b), (c), and (d): 100-h Test w/ Initial Test-End Cooling (e) and (f): 100-h Test w/ Modified Test-End Cooling

Figure 15a shows that the light area in the photograph was composed of $53.1 \mathrm{wt} \% \mathrm{Cr}, 34.1 \mathrm{wt} \% \mathrm{O}_{2}$, and $10.2 \mathrm{wt} \% \mathrm{Mn}$, while the dark area was composed of $33.0 \mathrm{wt} \%$ $\mathrm{Na}, 38.4 \mathrm{wt} \% \mathrm{~S}, 21.3 \mathrm{wt} \% \mathrm{O}_{2}$, and $5.6 \mathrm{wt} \% \mathrm{Mn}$. These data suggest that a layer of $\mathrm{Na}_{2} \mathrm{SO}_{4}$ was distributed on a thin oxide scale, shown in Fig. 15b. The AES data in Tables 5 and 6 show that sodium concentration in Specimen 304 SS-1 was high both on the surface (26.7 at.\%) and at a depth of $2700 \AA$ (21.1 at.\%), which confirms the SEM analyses. The SEM micrographs of 


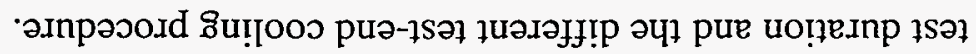

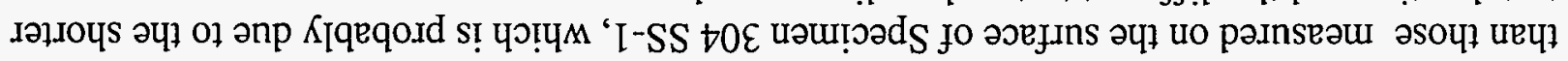

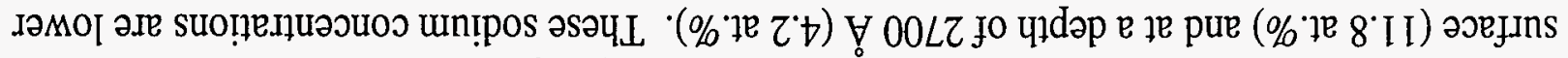

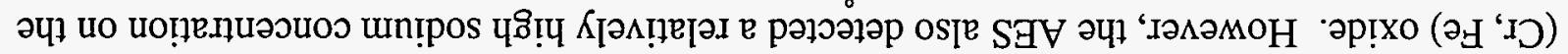

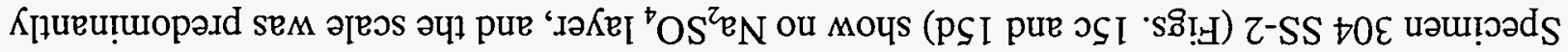

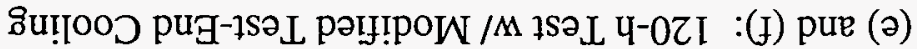

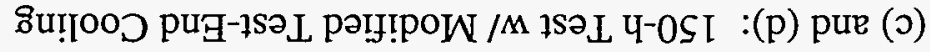

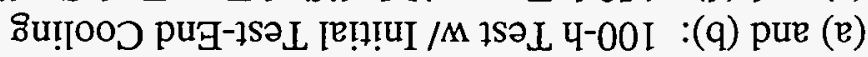

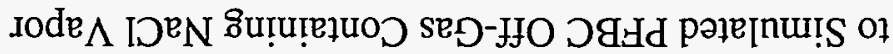
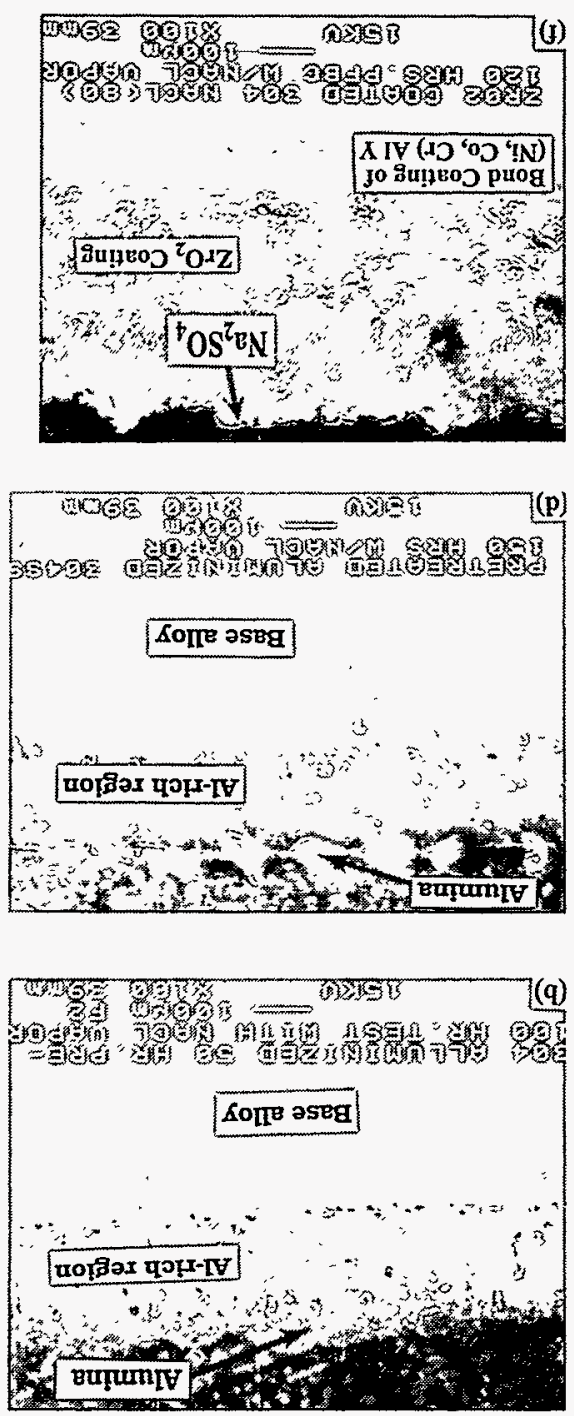
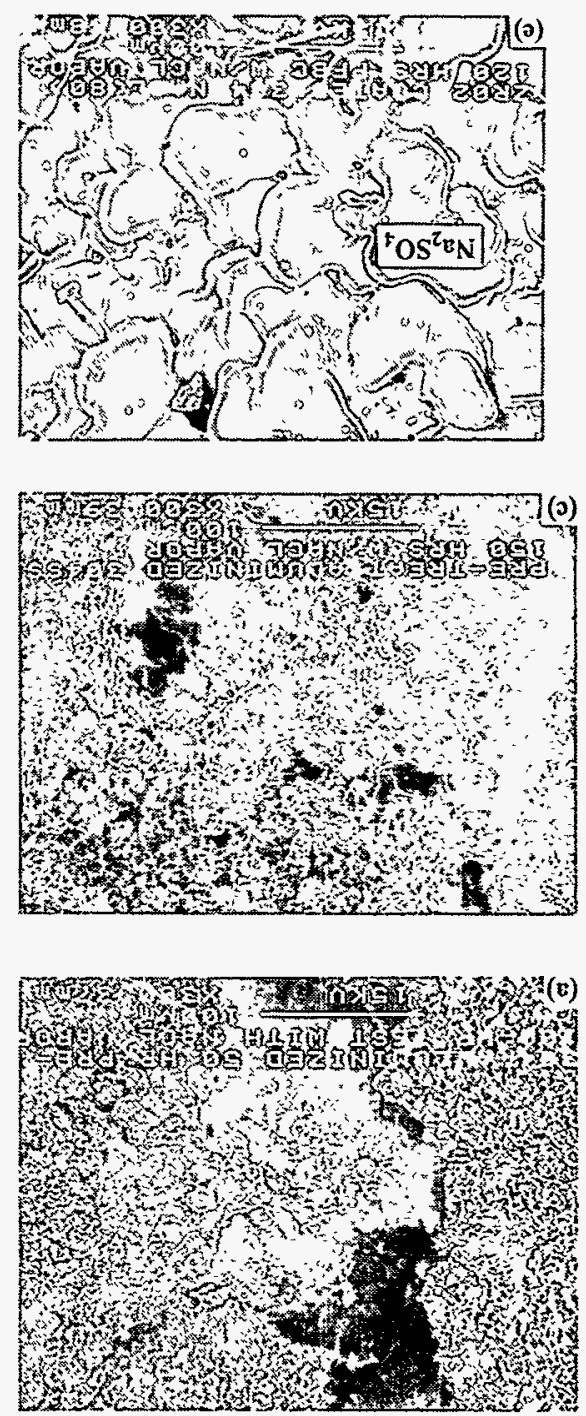
Table 5. AES Surface Concentrations in Coupon Specimens Exposed to Simulated PFBC Off-Gas Containing $\mathrm{NaCl}$ Vapor

\begin{tabular}{|c|c|c|c|c|c|c|c|c|}
\hline \multirow{2}{*}{ Specimen } & \multicolumn{8}{|c|}{ Elemental Analysis, at.\% } \\
\hline & 0 & $\mathrm{Cr}$ & $S$ & $\mathrm{Na}$ & $\mathrm{Fe}$ & $\mathrm{Mn}$ & $\mathrm{Al}$ & Other \\
\hline $304 S S-1^{2}$ & 35.6 & 9.1 & 4.4 & 26.7 & 7.5 & 11.6 & -- & P 5.0 \\
\hline $304 \mathrm{SS}-2^{b}$ & 55.5 & 6.1 & 2.5 & 11.8 & 20.9 & -- & -- & $\mathrm{Cl} 2.8$ \\
\hline Hastelloy $\mathrm{X}^{\mathrm{c}}$ & 38.2 & 2.3 & 4.8 & 28.6 & 4.8 & 5.5 & -- & $\begin{array}{l}\mathrm{P} 4.6, \mathrm{Cl} 2.2, \\
\mathrm{Co} 4.1, \mathrm{Ni} 3.4\end{array}$ \\
\hline Hastelloy C-276 & $\mathrm{NA}$ & & & & & & & \\
\hline Haynes No. $188^{e}$ & 42.1 & 7.9 & 4.0 & 19.0 & 5.0 & -- & -- & $\begin{array}{c}\text { P } 3.4, \mathrm{Cl} 0.8, \\
\text { Co } 10.9, \text { Ni } 6.9\end{array}$ \\
\hline $\mathrm{Pt} / 304 \mathrm{SS}^{\mathrm{f}}$ & 49.9 & 7.9 & 3.0 & 20.2 & 6.3 & 10.1 & -- & -- \\
\hline $\mathrm{Au} / 304 \mathrm{SS}^{\mathrm{g}}$ & 49.3 & 6.4 & 3.7 & 16.1 & 24.2 & -- & -- & -- \\
\hline $\mathrm{Ag} / 304 \mathrm{SS}^{\mathrm{h}}$ & 45.1 & 11.7 & 2.2 & 15.3 & 22.0 & - & -- & $\mathrm{Ni} 2.5$ \\
\hline $\mathrm{Al} / 304 \mathrm{SS}-1^{\mathrm{i}}$ & 7.4 & -- & 0.9 & 6.1 & -- & - & 85.6 & - \\
\hline $\mathrm{Al} / 304 \mathrm{SS}-2^{\mathrm{J}}$ & 57.9 & -- & 1.2 & 8.5 & 10.9 & -- & 21.3 & -- \\
\hline $\mathrm{ZrO}_{2} / 304 \mathrm{SS}^{\mathrm{k}}$ & 28.8 & -- & 7.8 & 26.7 & - & -- & - & $\mathrm{Zr} 28.3, \mathrm{P} 7.4$ \\
\hline
\end{tabular}

${ }^{3}$ The specimen and the $\mathrm{NaCl}$ bed were cooled simultaneously at the end of the test (referred to as initial test-end cooling).

${ }^{b}$ A duplicate test for $90 \mathrm{~h}$. The $\mathrm{NaCl}$ bed was first cooled to $<400^{\circ} \mathrm{C}$ and then the specimen was cooled (referred to as modified test-end cooling).

${ }^{c}$ Initial test-end cooling.

"Not analyzed due to severe corrosion of the tested specimen.

' Initial test-end cooling.

'Pt-Coated 304 SS, initial test-end cooling.

${ }^{8} \mathrm{Au}$-Coated 304 SS, initial test-end cooling.

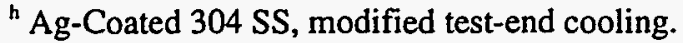

' Pretreated (at $1000^{\circ} \mathrm{C}$ for $50 \mathrm{~h}$ in air) aluminized $304 \mathrm{SS}$, initial test-end cooling.

${ }^{\mathrm{j}} \mathrm{A}$ duplicate test for $150 \mathrm{~h}$ with modified test-end cooling.

${ }^{\mathrm{k}} \mathrm{ZrO}_{2}$-coated $304 \mathrm{SS}$, modified test-end cooling.

The presence of $\mathrm{Mn}, \mathrm{Fe}$, and $\mathrm{Cr}$, and the substantial amount of oxygen on the surface of the 304 SS specimens (Tables 5 and 6 ) indicate that the captured sodium could be reacting with the base metal elements to form complex ( $\mathrm{Na}, \mathrm{Cr}, \mathrm{Mr}, \mathrm{Fe})$ oxides as reaction products. The analysis shows that the relative ratios of $\mathrm{Na}: \mathrm{M}: \mathrm{O}$ at the surface and at a depth of $2700 \AA$ of Specimen 304 SS- 1 are $~ 3: 3: 4$ and 2:3:4, respectively, where $M$ represents the total concentrations of $\mathrm{Fe}, \mathrm{Cr}$, and $\mathrm{Mn}$. The corresponding ratios for Specimen $304 \mathrm{SS}-2$ are $~ 1.5: 3: 6$ and $~ 0.5: 4: 6$. These results indicate that in both specimens the sodium concentration was much greater at the surface than at $2700 \AA$. 
Table 6. AES Surface Concentrations at a Depth of $2700 \AA$ in Coupon Specimens Exposed to Simulated PFBC Off-Gas Containing $\mathrm{NaCl}$ Vapor

\begin{tabular}{|c|c|c|c|c|c|c|c|c|}
\hline \multirow{2}{*}{ Specimen $^{2}$} & \multicolumn{8}{|c|}{ Elemental Analysis, at.\% } \\
\hline & $\mathrm{O}$ & $\mathrm{Cr}$ & $S$ & $\mathrm{Na}$ & $\mathrm{Fe}$ & $\mathrm{Mn}$ & $\mathrm{Al}$ & Other \\
\hline 304 SS-1 & 40.3 & 15.6 & 4.5 & 21.1 & 3.3 & 11.0 & - & P 3.3 \\
\hline 304 SS-2 & 54.9 & 10.1 & 0.6 & 4.2 & 25.8 & - & -- & $\mathrm{Ni} 4.4$ \\
\hline Hastelloy X & 37.8 & 4.1 & 8.0 & 20.3 & 5.6 & 5.1 & -- & P 8.3 \\
\hline Hastelloy C-276 & NA & -- & -- & -- & -- & -- & - & -. \\
\hline Haynes No. 188 & 43.4 & 8.1 & 4.7 & 11.6 & 2.3 & -- & -- & $\begin{array}{c}\text { P 2.3, Ni } 6.7 \\
\text { Co } 15.7\end{array}$ \\
\hline $\mathrm{Pt} / 304 \mathrm{SS}$ & 53.7 & 16.4 & 4.4 & 10.6 & 4.6 & 10.3 & -- & P 4.6 \\
\hline $\mathrm{Au} / 304 \mathrm{SS}$ & 54.3 & 5.1 & 2.0 & 7.8 & 31.0 & - & - & - \\
\hline $\mathrm{Ag} / 304 \mathrm{SS}$ & 45.9 & 8.8 & 3.2 & 7.7 & 28.6 & - & -- & Ni 5.1, Ag 0.7 \\
\hline $\mathrm{Al} / 304 \mathrm{SS}-1$ & 33.6 & 8.1 & 6.6 & 14.3 & 9.4 & -- & 28.1 & - \\
\hline $\mathrm{Al} / 304 \mathrm{SS}-2$ & 35.2 & 5.6 & 1.6 & 10.0 & 7.7 & -- & 39.9 & -- \\
\hline $\mathrm{ZrO}_{2} / 304 \mathrm{SS}$ & 32.5 & -- & 7.7 & 24.0 & -- & - & -- & $\mathrm{Zr} 28.3, \mathrm{P} 7.4$ \\
\hline
\end{tabular}

${ }^{a}$ Sample identification is given in Table 5 .

Some chlorine (2.8 at.\%) was detected on the surface of Specimen 304 SS-2 (Table 5), indicating the adsorption of $\mathrm{NaCl}$ vapor on the $\mathrm{Cr}_{2} \mathrm{O}_{3}$ scale. This observation may suggest that $\mathrm{NaCl}$ vapor was initially adsorbed on the surface and then gradually reacted with adsorbed $\mathrm{SO}_{2}, \mathrm{O}_{2}$, and $\mathrm{H}_{2} \mathrm{O}$ vapor to form the $\mathrm{Na}_{2} \mathrm{SO}_{4}$ layer (as observed by $\mathrm{SEM}$ ) according to the following reaction:

$$
2 \mathrm{NaCl}(\mathrm{ad})+\mathrm{SO}_{2}(\mathrm{ad})+1 / 2 \mathrm{O}_{2}(\mathrm{ad})+\mathrm{H}_{2} \mathrm{O}(\mathrm{ad})=\mathrm{Na}_{2} \mathrm{SO}_{4(\mathrm{~s})}+2 \mathrm{HCl}(\mathrm{g})
$$

Results of this test are in agreement with earlier observations that the heated $\left(840-950^{\circ} \mathrm{C}\right) 304 \mathrm{SS}$ sampling line used in the on-line alkali analyzer captures $\mathrm{NaCl}$ and $\mathrm{KCl}$ vapors when exposed to $\mathrm{NaCl}-\mathrm{KCl}$-vapor-bearing simulated PFBC off-gas. ${ }^{20,21}$

\subsubsection{Hastelloy X}

The first test of Hastelloy $\mathrm{X}$ was completed by using initial test-end cooling. The SEM micrographs of the after-test specimen are shown in Figs. 15e (surface) and $15 \mathrm{f}$ (crosssection). The specimen developed a $(\mathrm{Cr}, \mathrm{Fe}$ ) oxide scale, $\sim 5 \mu \mathrm{m}$ thick, in contrast to the pure $\mathrm{Cr}_{2} \mathrm{O}_{3}$ scale, 2-3 $\mu \mathrm{m}$ thick, that formed on the specimen exposed to the baseline PFBC off-gas. The EDX analysis showed the dark regions in Fig. 15e to be predominantly $\mathrm{Na}, \mathrm{S}$, and $\mathrm{O}$, suggesting that a $\mathrm{Na}_{2} \mathrm{SO}_{4}$ layer deposited on the oxide scale, as shown in Fig. 15f. The light areas of Fig. 15e were chromium-rich oxide with very little sulfur. The boundary between the dark 
and light areas contained $\mathrm{Ni}, \mathrm{Cr}, \mathrm{O}$, and $\mathrm{S}$. $\mathrm{No} \mathrm{Na}$ or $\mathrm{Cl}$ was detected. The $\mathrm{AES}$ analyses of the specimen showed similarly high sodium concentrations as measured for Specimen 304 SS-1 both on the surface ( 28.6 at.\%) and at a depth of $2700 \AA$ (20.3 at.\%). These results confirm the SEM observations. The AES analysis also detected a small amount (2.2 at.\%) of chlorine on the surface of the specimen.

A duplicate test was conducted using the modified test-end cooling procedure; Figs. $15 \mathrm{~g}$ and $15 \mathrm{~h}$ show the SEM micrographs. $\mathrm{A} \mathrm{Na}_{2} \mathrm{SO}_{4}$ deposit layer was also observed on this specimen and the scaling characteristics with regard to morphology and composition were similar to those observed in the first test.

\subsubsection{Hastelloy C-276}

As shown in SEM micrographs (Figs. 16a and 16b), the Hastelloy C-276 sustained severe corrosive attack and substantial internal sulfidation in the PFBC test. Corrosion was equally severe after only $25 \mathrm{~h}$ exposure (Fig. 16c). It is evident that the oxide scale in this alloy did not protect against $\mathrm{NaCl}$ vapor attack. On the other hand, Hastelloy $\mathrm{X}$ exhibited virtually no signs of corrosive attack under the same test conditions. The enhanced attack on Hastelloy C-276 can be attributed to the lower chromium content of the alloy (15.5 wt\%) compared with the Hastelloy X (22 wt\%).

The EDX analysis (Fig. 12) of the after-test specimen showed that the thick outermost layer consisted of $\mathrm{NiO}$ and chromium sulfides. The inner layer contained $\mathrm{Ni}, \mathrm{Cr}, \mathrm{Fe}$, and $\mathrm{O}$. The interior of the specimen had significant precipitates of sulfides in the grain boundary regions. The extent of corrosion was very severe and the corrosion product layers were much more complex than in other alloys tested; as a result, EDX analysis could not detect the presence of $\mathrm{Na}$ or $\mathrm{Cl}$.

\subsubsection{Haynes No. 188}

Figures 16d and 16e are SEM micrographs of the exposed coupon (initial test-end cooling procedure). The EDX analysis showed that the fine-grained area in Fig. 16d consisted of chromium-rich oxide, the dark areas were rich in sodium, and the larger particles were cobalt oxide. The cross section of the specimen (Fig. 16e) showed the outmost layer to be rich in sodium salt while the internal continuous layer was oxide scale. The interior of the specimen contained chromium-rich sulfides and tungsten-containing oxides. The AES analysis (Tables 5 and 6) of the specimen showed significant sodium concentrations on the surface (19.0 at.\%) and at $2700 \AA$ ( 11.6 at.\%). These data are in agreement with the EDX analysis. A small amount ( 0.8 at.\%) of chlorine was also detected by AES on the surface of the specimen. A duplicate test completed with the modified test-end cooling procedure also revealed sodium salt on the exposed after-test specimen, as shown in Fig. 16f.

\subsubsection{Noble-Metal-Coated 304 SS}

Figure 17 shows SEM micrographs for surfaces and cross sections of Pt-, Au-, and Ag-coated $304 \mathrm{SS}$ coupons. Testing of the first two coupons was completed by using the 
initial test-end cooling procedure, while the Ag-coated specimen was cooled with the modified test-end procedure. The EDX analyses of after-test specimens showed that the Pt-coated specimen developed a thin scale, predominantly chromium oxide. The morphology of the $\mathrm{Pt}$-enriched near-surface indicates that strong Fe-Pt interactions prevent iron transport while enabling transport of chromium outwards from the bulk alloy. By contrast, the $\mathrm{Au}$ - and Ag-coated specimens developed a predominantly iron oxide scale, which was much thinner in the Au-coated than in the Ag-coated specimen. Substantial segregation of Au and Ag was observed at the scale/alloy interface, indicating that a $\mathrm{Au}$ or $\mathrm{Ag}$ coating does not act as a barrier against outward diffusion and subsequent oxidation of iron from the bulk alloy. Some sulfides were observed in the interior of the specimens.

Some sodium was observed in the EDX analyses of the surfaces of these specimens but it was intermixed with the alloy/coating constituents, indicating that sodium capture is confined to a very thin layer on the surface. The AES analyses gave concentrations of 20.2, 16.1, and 15.3 at.\% on surfaces of Pt-, Au-, and Ag-coated specimens, respectively, as shown in Table 5. Sodium concentrations decreased to 10.6,7.8, and 7.7 at.\% at a depth of $2700 \AA$, as shown in Table 6 . The test-end cooling procedure used in carrying out the shut-down of the test did not appear to have any significant effect on the sodium concentration.

\subsubsection{Aluminized 304 SS}

Figures $18 \mathrm{a}$ and $18 \mathrm{~b}$ show SEM micrographs for the surface and the cross section, respectively, of the exposed aluminized 304 SS specimen. Cooling was according to the initial test-end procedure. The SEM micrographs from a duplicate test (150-h exposure, cooling by the modified test-end cooling procedure) are shown in Figs. $18 \mathrm{c}$ and $18 \mathrm{~d}$. These figures show that the continuous $\mathrm{Al}_{2} \mathrm{O}_{3}$ scale developed during the pretreatment remained intact after exposure (as in the baseline test), and no sulfur was detected in the scale or the alloy substrate.

The AES analyses (Tables 5 and 6 ) of these two specimens showed the presence of sodium on the surface (6.1 and 8.5 at.\% for $100-\mathrm{h}$ and 150 -h tests, respectively) and at $2700 \AA$ (14.3 and 10.0 at.\%). The surface sodium concentration of this aluminized 304 SS was the lowest of all the specimens tested, as shown in Table 5.

\subsection{7 $\quad \mathrm{ZrO}_{2}$-Coated 304 SS}

The $\mathrm{ZrO}_{2}$-coated $304 \mathrm{SS}$ coupon was exposed for $120 \mathrm{~h}$, and cooled with the modified test-end cooling procedure. The EDX analysis of the surface of the exposed specimen showed predominantly $\mathrm{Na}, \mathrm{S}, \mathrm{O}$, and $\mathrm{Zr}$, and virtually no $\mathrm{Cl}$. Figures $18 \mathrm{e}$ and $18 \mathrm{f}$ show SEM micrographs of the surface and the cross section, respectively, of the exposed specimen. The specimen had a fairly uniform deposit layer of $\mathrm{Na}_{2} \mathrm{SO}_{4}$ with a $30-\mu \mathrm{m}$ diameter globular shape, as shown in Fig. 18e. The deposit exhibited some porosity, accompanied by chipping and cracking of the coating in a few areas.

The photomicrograph of the cross section of the exposed specimen (Fig. 18f) showed that the bond layer and the $\mathrm{ZrO}_{2}$ coating were approximately 100 and $500 \mu \mathrm{m}$ thick, 
respectively. The sodium-rich area was confined to the surface region $\left(\sim 1 \mu \mathrm{m}\right.$ thick) of the $\mathrm{ZrO}_{2}$ coating. This is in agreement with the AES spectra shown in Tables 5 and 6 , which indicate sodium concentrations of 26.7 at.\% on the surface and 24.0 at.\% at a depth of $2700 \AA$. The EDX analysis of the cross sections of the exposed specimens showed that the bond coat developed alumina at the grain boundary/crack regions of the bond coat, indicating that the $\mathrm{ZrO}_{2}$ coating was not impervious to gaseous diffusion.

\subsection{Tests in Baseline Simulated Gasification Fuel Gas}

The simulated gasification fuel gas (Section 2.2) consisted predominantly of $\mathrm{CO}$ and $\mathrm{H}_{2}$, which resulted in an extremely low partial pressure of oxygen in the exposure environment. The sulfur was present as $\mathrm{H}_{2} \mathrm{~S}$, not $\mathrm{SO}_{2}$ as in the simulated $\mathrm{PFBC}$ environment. The gas for the baseline test did not contain any $\mathrm{NaCl}$. Two materials, namely, aluminized $304 \mathrm{SS}$ and Haynes No. 188 alloy were exposed to fuel gas for 90 and $100 \mathrm{~h}$, respectively, at $870-875^{\circ} \mathrm{C}$. Since no alkali chloride was present in the baseline test, the scaling of the alloys was influenced by the oxidation and sulfidation reactions that can occur between the substrate constituents and the oxygen and sulfur reactants in the gas phase.

At the end of the test, both aluminized 304 SS and Haynes No. 188 specimens had become black. Table 7 shows the total weight gain of the specimens. Both specimens, especially the aluminized 304 SS, gained significantly more weight than in the simulated PFBC off-gas exposure (Table 3).

Table 7. Total Weight Gain of Aluminized 304 SS and Haynes No. 188 under Baseline Simulated Gasification Fuel Gas (No NaCl Vapor)

\begin{tabular}{||c|c|c|c||}
\hline Material & $\begin{array}{c}\text { Specimen Dimensions, } \\
\mathrm{cm}\end{array}$ & $\begin{array}{c}\text { Initial Wt, } \\
\mathrm{g}\end{array}$ & $\begin{array}{c}\text { Total Wt Change, } \\
\mathrm{mg} / \mathrm{cm}^{2}\end{array}$ \\
\hline Aluminized 304 SS & $1.27 \times 1.27 \times 0.127$ & 1.8210 & +27.64 \\
\hline Haynes No. 188 & $2.06 \times 1.43 \times 0.127$ & 2.9984 & +0.55 \\
\hline
\end{tabular}

${ }^{2} \mathrm{~L} \times \mathrm{W} \times \mathrm{T}$.

'Weight change after 90- and 100-h exposure for aluminized 304 SS and Haynes No. 188, respectively.

'The specimen had been preheated in air at $1000^{\circ} \mathrm{C}$ for $50 \mathrm{~h}$.

Figure 19 shows SEM micrographs of the surface and cross section of the aluminized 304 SS specimen, and Fig. 20 shows EDX spectra for the specimen surface and at several locations identified as A, B, C, D, and E in Fig. 19. As indicated earlier (Fig. 8c), a continuous $\mathrm{Al}_{2} \mathrm{O}_{3}$ scale was originally developed during a $1000^{\circ} \mathrm{C}$ pretreatment of the specimen. After exposure for $100 \mathrm{~h}$ to the simulated PFBC off-gas (oxidizing), this $\mathrm{Al}_{2} \mathrm{O}_{3}$ scale remained intact (Fig. 11h), and no sulfur was detected in the scale and the alloy substrate. By contrast, exposure to the simulated gasification fuel gas (reducing) subjected the $\mathrm{Al}_{2} \mathrm{O}_{3}$ scale to attack by $\mathrm{H}_{2} \mathrm{~S}$ in isolated regions, as shown by the dark locations, B, D, and E, in Fig. 19. 

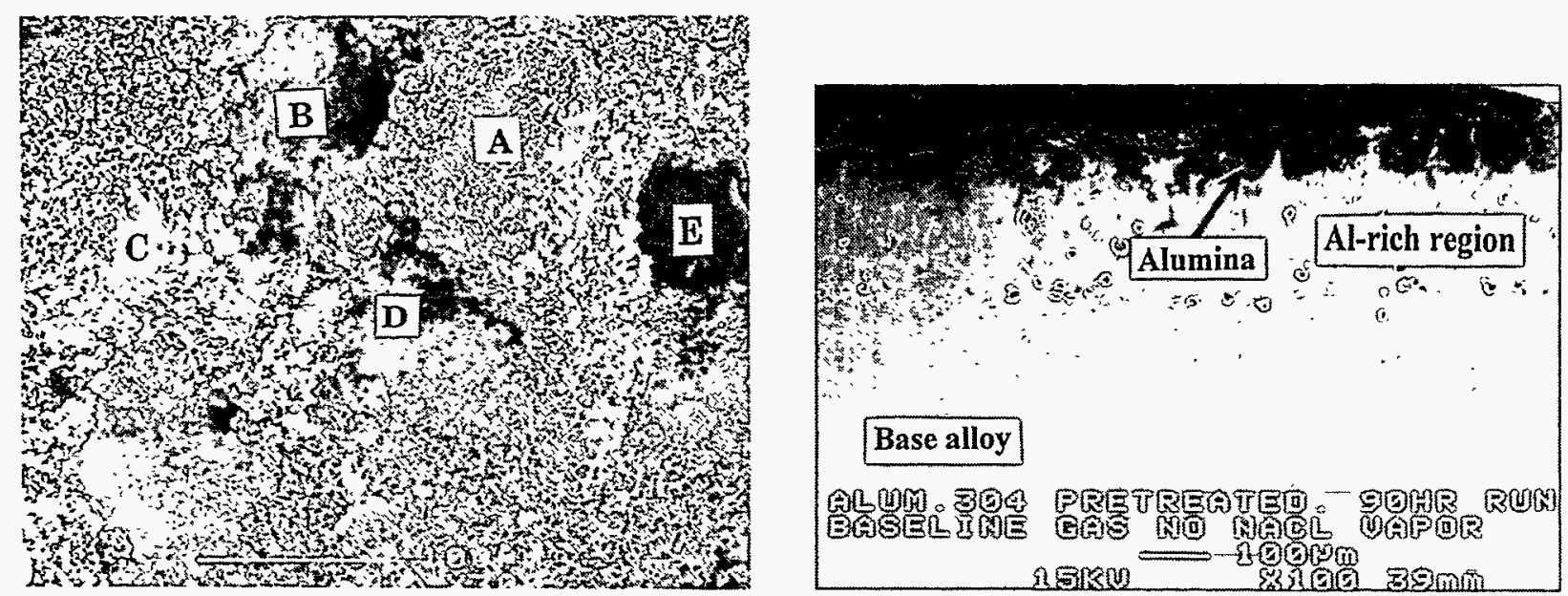

Fig. 19. SEM Micrographs of Surface (Left) and Cross Section (Right) of Aluminized 304 SS after Exposure to Baseline Simulated Gasification Fuel Gas (No NaCl Vapor). Results of EDX analysis for locations A, B, C, D, and E are shown in Fig. 20.

The formation of $(\mathrm{Cr}, \mathrm{Mn}, \mathrm{Fe})$ sulfides in these regions is seen in the EDX analysis in Fig. 20. Apparently, this sulfide formation resulted in the substantial weight gain shown in Table 7. The lighter regions, $\mathrm{A}$ and $\mathrm{C}$, in Fig. 19 are basically the intact $\mathrm{Al}_{2} \mathrm{O}_{3}$ scale, as indicated in the EDX analyses in Fig. 20.

Figure 21 shows SEM micrographs for the surface and cross section and EDX spectra for locations $A$ and $B$ on the surface of the Haynes No. 188 specimen after baseline exposure. The specimen formed a continuous, uniform black scale on the surface. The EDX analysis showed that the scale consists of chromium-rich ( $\mathrm{Cr}, \mathrm{Mn}, \mathrm{Fe}$ ) oxides, and a trace amount of sulfur was detected on the surface of the specimen. In the simulated PFBC off-gas (Fig. 12c) by contrast, only $\mathrm{Cr}_{2} \mathrm{O}_{3}$ scale was formed and no sulfur was detected in the scale and the alloy substrate.

\subsection{Test in Simulated Gasification Fuel Gas Containing NaCl Vapor}

For this test, the aluminized 304 SS and Haynes No. 188 coupons were hung together in the TGA setup (Fig. 10) and exposed simultaneously to the simulated gasification fuel gas containing $80 \mathrm{ppmW} \mathrm{NaCl}$ vapor at $870-875^{\circ} \mathrm{C}$ for $70 \mathrm{~h}$. Table 8 summarizes the total weight gain of the two specimens. The aluminized $304 \mathrm{SS}$ was found to be badly corroded, resulting in the unusually large weight gain shown in Table 8 . Some black scale peeled off easily during handling of the tested specimen. As in earlier tests, the initially shiny Haynes No. 188 specimen became black after testing. 

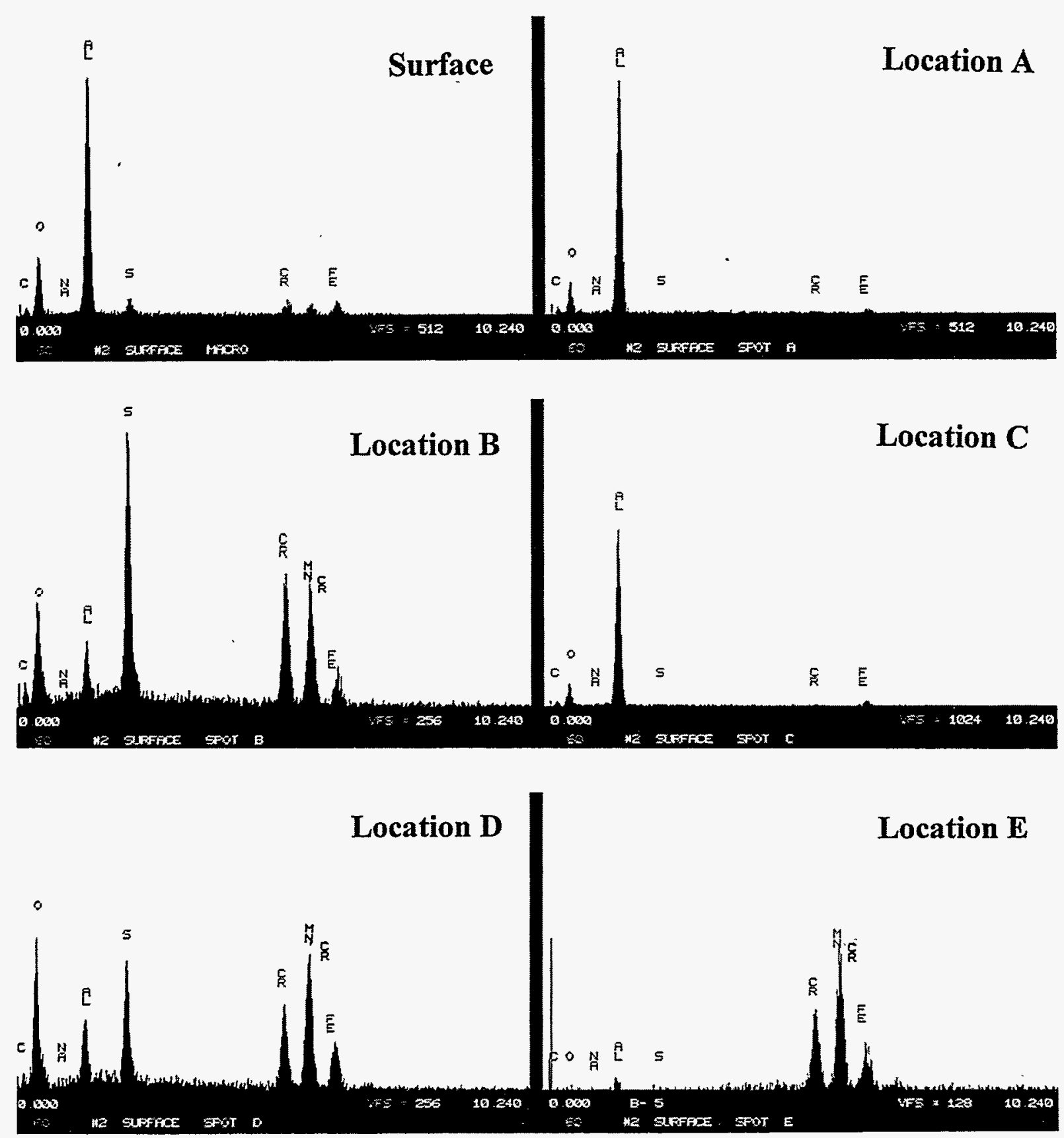

Fig. 20. EDX Spectra of the Surface of Aluminized 304 SS after Exposure to Baseline Simulated Gasification Fuel $\mathrm{Gas}$ (No $\mathrm{NaCl}$ vapor). Locations A, B, C, D, and E are identified in Fig. 19.

\subsubsection{Aluminized 304 SS}

Figure 22 shows SEM micrographs for the surface and cross section and EDX spectra at several locations identified as A, B, and C of the surface of the aluminized 304 SS 


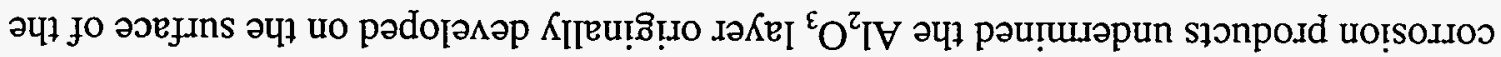

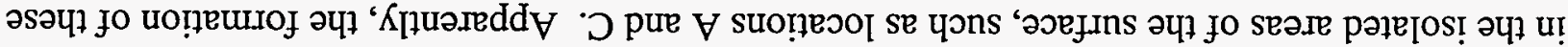

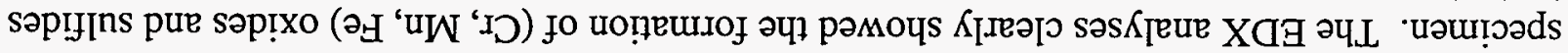

\section{$(\operatorname{Iode} \Lambda$ IDeN ON)}

SED [əח

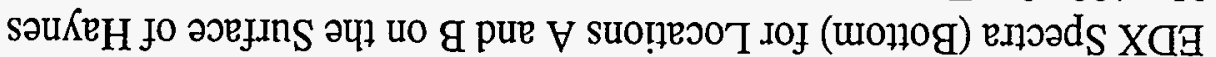

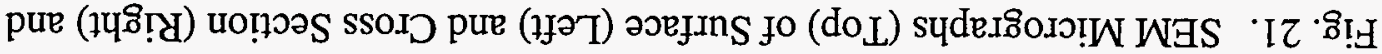

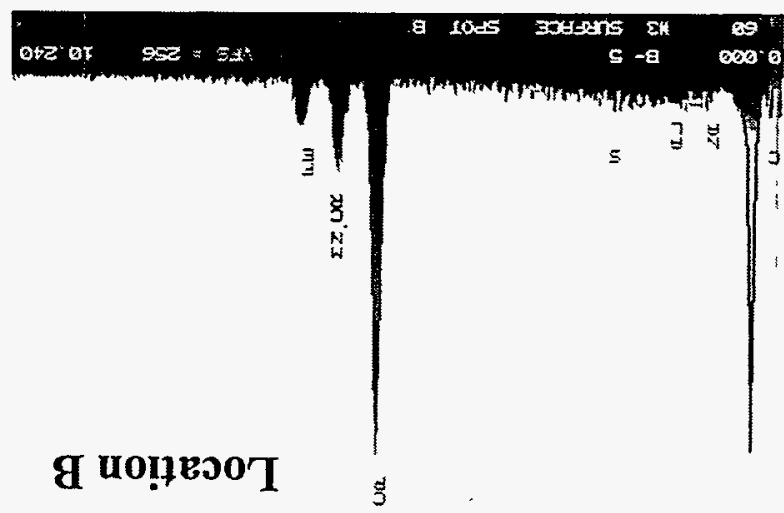

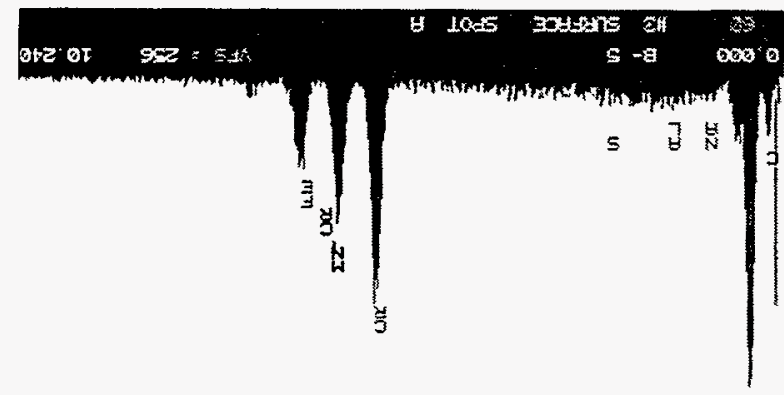

V นọ̣อวoT

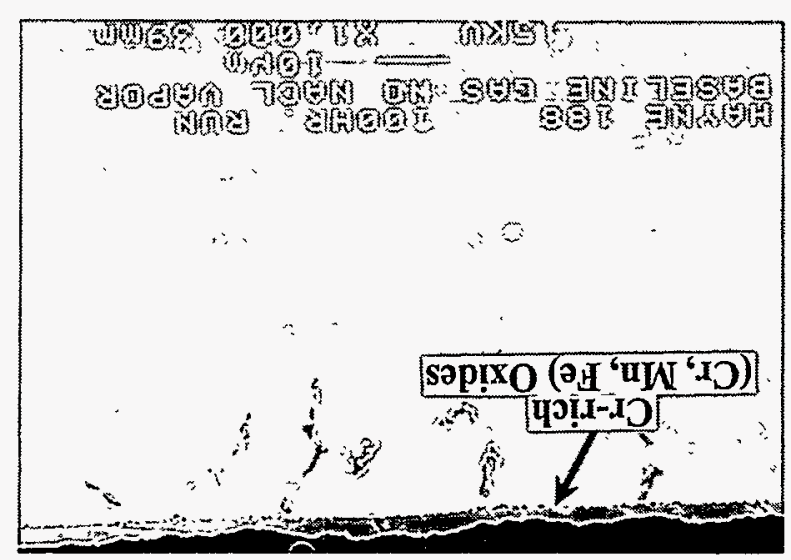

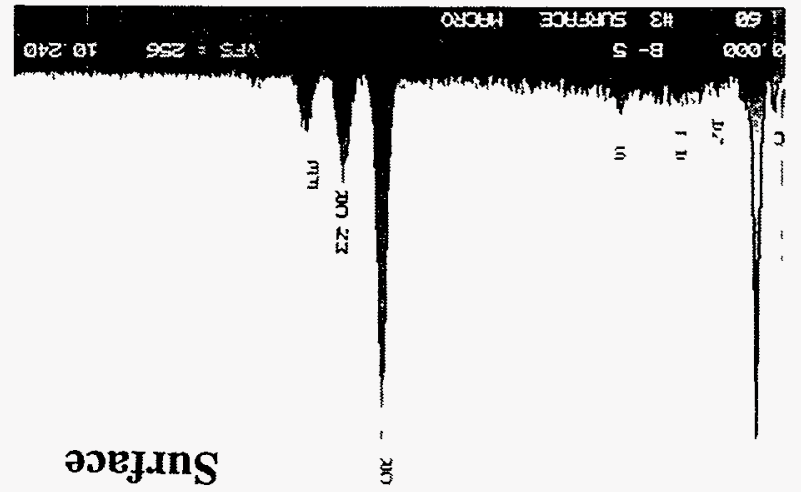

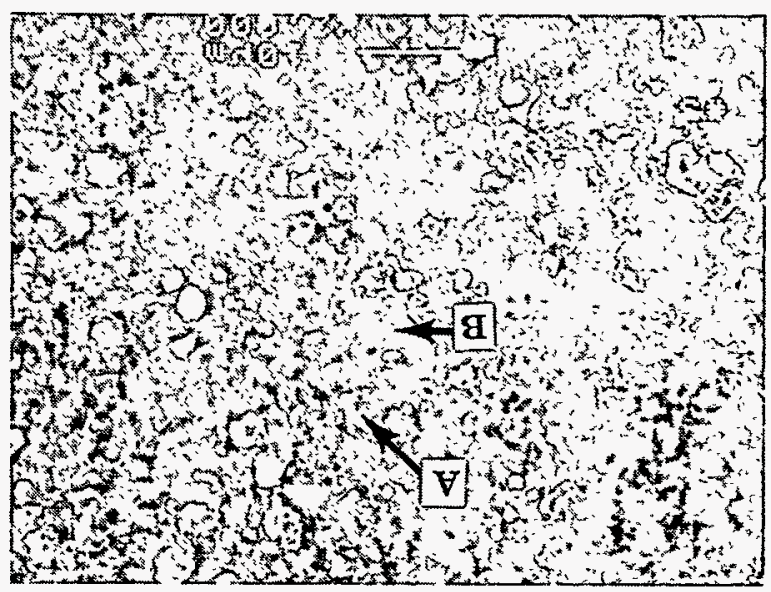


Table 8. Total Weight Gain of Aluminized 304 SS and Haynes No. 188 under Simulated Gasification Fuel Gas Containing $\mathrm{NaCl}$ Vapor

\begin{tabular}{|c|c|c|c|}
\hline Material & $\begin{array}{c}\text { Specimen Dimensions, } \\
\mathrm{cm}\end{array}$ & $\begin{array}{c}\text { Initial Wt, } \\
\mathrm{g}\end{array}$ & $\begin{array}{c}\text { Total Wt Change, } \\
\mathrm{mg} / \mathrm{cm}^{2}\end{array}$ \\
\hline Aluminized 304 $\mathrm{SS}^{\mathrm{c}}$ & $1.27 \times 1.27 \times 0.127$ & 1.8155 & +41.82 \\
\hline Haynes No. 188 & $1.27 \times 0.635 \times 0.127$ & 0.8460 & +0.81 \\
\hline
\end{tabular}

${ }^{\mathrm{a}} \mathrm{L} \times \mathrm{W} \times \mathrm{T}$.

${ }^{b}$ Weight change after 70-h exposure.

'The specimen had been preheated in air at $1000^{\circ} \mathrm{C}$ for $50 \mathrm{~h}$.

specimen during pretreatment and caused the $\mathrm{Al}_{2} \mathrm{O}_{3}$ scale to spall off the surface. This is shown in the cross-section SEM micrograph, in which the originally developed continuous $\mathrm{Al}_{2} \mathrm{O}_{3}$ scale disappeared from the tested specimen.

The EDX analyses also showed the presence of sodium along with sulfur on the surface of the $\mathrm{Al}_{2} \mathrm{O}_{3}$ scale (EDX spectra for surface and location $\mathrm{B}$ ), but not in the corroded locations ( $\mathrm{A}$ and $\mathrm{C}$ ). This suggests the affinity of the $\mathrm{Al}_{2} \mathrm{O}_{3}$ scale for sodium adsorption. Detailed analysis of the specimen cross section showed that the sodium adsorbed layer was confined to a layer $\sim 1 \mu \mathrm{m}$ thick at the surface of the aluminized region.

\subsubsection{Haynes No. 188}

Figure 23 shows SEM micrographs for the surface and cross section and EDX spectra of the surface of the exposed Haynes No. 188 specimen. As in the baseline exposure, the specimen developed a continuous, uniform, black oxide scale on the surface, more noticeably in isolated locations. However, virtually no sodium was detected in this Haynes No. 188 specimen, indicating that the scale lacks sorption affinity for $\mathrm{NaCl}$ vapor. This is in contrast to the $\mathrm{Cr}_{2} \mathrm{O}_{3}$ scale developed in the oxidizing PFBC off-gas environment, on which $\mathrm{NaCl}$ vapor was shown to be adsorbed and gradually converted into $\mathrm{Na}_{2} \mathrm{SO}_{4}$.

\subsection{CONCLUSIONS AND RECOMMENDATIONS}

All nine candidate materials, 304 SS, Hastelloy C-276, Hastelloy X, Haynes No. 188, Pt-coated 304 SS, Au-coated 304 SS, Ag-coated 304 SS, aluminized 304 SS and $\mathrm{ZrO}_{2}$-coated $304 \mathrm{SS}$, showed various degrees of $\mathrm{NaCl}$-vapor adsorption after exposure at $870-875^{\circ} \mathrm{C}$ to the simulated PFBC off-gas (oxidizing) containing $80 \mathrm{ppmW} \mathrm{NaCl}$ vapor. The aluminized $304 \mathrm{SS}$ exhibited the least tendency to adsorb $\mathrm{NaCl}$ vapor, as well as an excellent resistance to corrosion as a result of the formation of the protecting $\mathrm{Al}_{2} \mathrm{O}_{3}$ layer on the surface. In the simulated gasification fuel gas (reducing) containing $80 \mathrm{ppmW} \mathrm{NaCl}$ vapor, however, the aluminized 304 SS was badly corroded by $\mathrm{H}_{2} \mathrm{~S}$ attack, whereas the Haynes No. 188 showed virtually no $\mathrm{NaCl}$-vapor adsorption and only limited $\mathrm{H}_{2} \mathrm{~S}$ attack. 

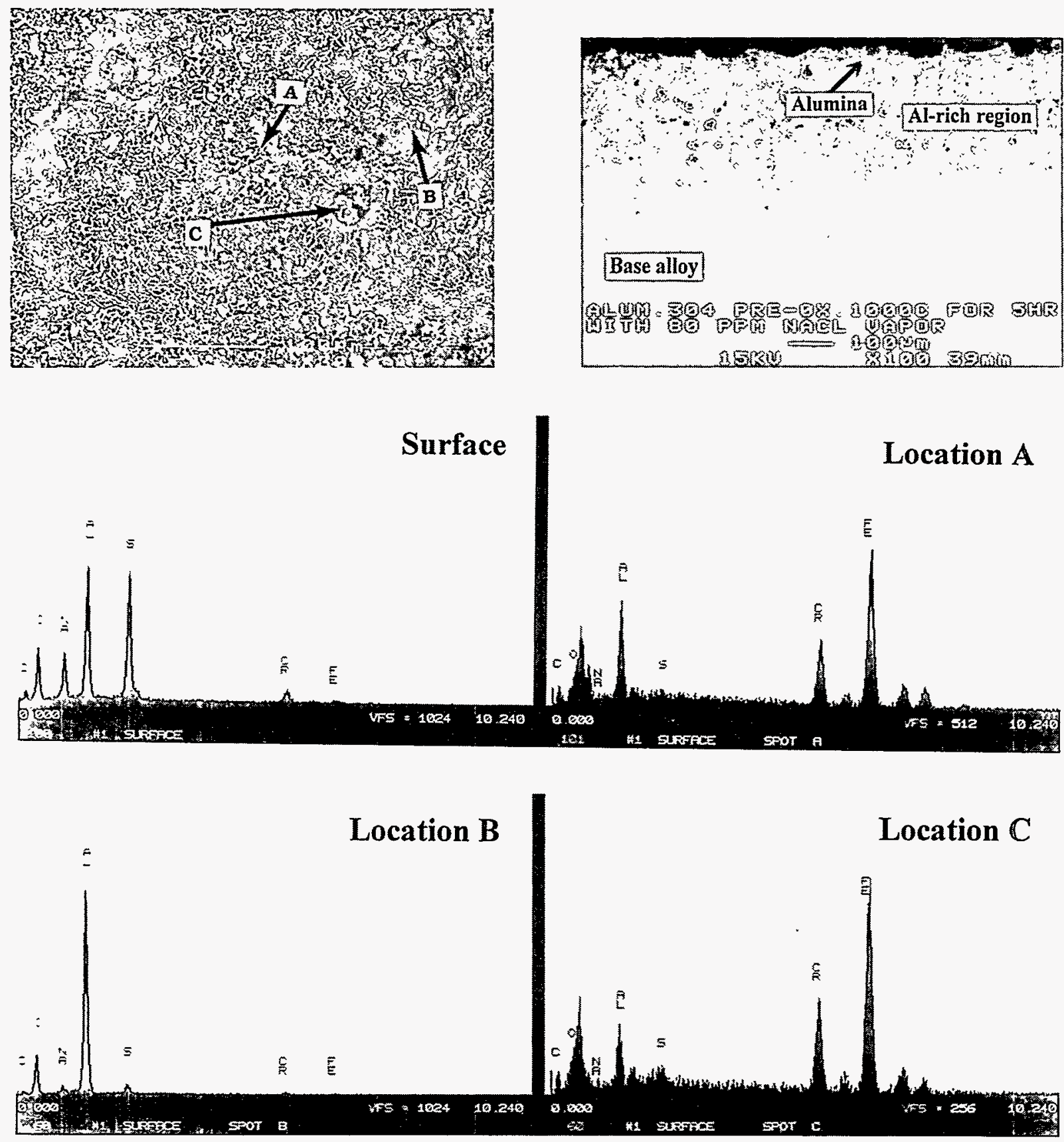

Fig. 22. SEM Micrographs (Top) of Surface (Left) and Cross Section (Right) and EDX Spectra (Bottom) for Locations A, B, and C on the Surface of Aluminized 304 SS after Exposure to Simulated Gasification Fuel Gas Containing $\mathrm{NaCl}$ Vapor

This work was designed to be a preliminary screening study to identify material(s) that possesses little or no affinity for alkali vapor. Based on results of this study, we recommend performance of long-term parametric studies on alkali-vapor adsorption by (1) the aluminized 

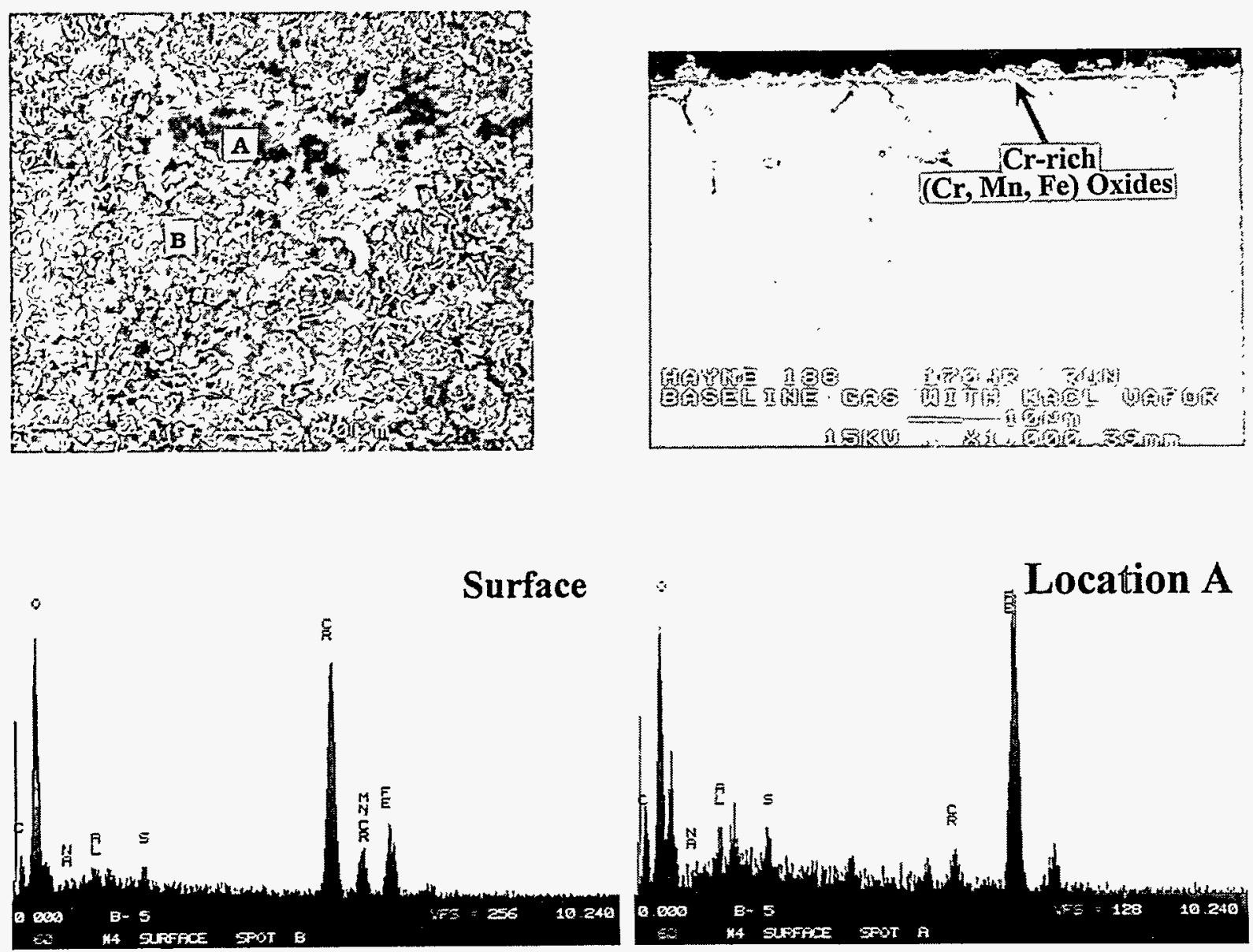

Location B

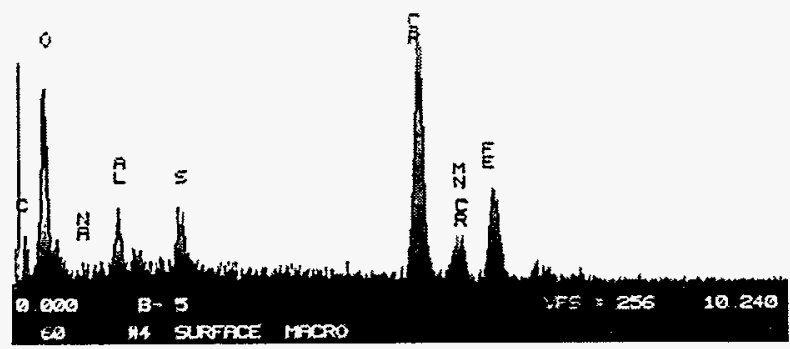

Fig. 23. SEM Micrographs (Top) of Surface (Left) and Cross Section (Right) and EDX Spectra (Bottom) for Locations A and B on the Surface of Haynes No. 188 after Exposure to Simulated Gasification Fuel Gas Containing $\mathrm{NaCl}$ Vapor

304 SS in the PFBC off-gas environment and (2) the Haynes No. 188 in the gasification fuel gas environment. It will be valuable to obtain quantitative estimates of alkali-vapor adsorption by these materials as a function of operating variables, for example, temperature, pressure, exposure duration, and the level of alkali-vapor concentration in the gas stream. The control of alkali vapor to a few parts per million is recommended. 


\subsection{ACKNOWLEDGMENTS}

The authors are pleased to acknowledge D. L. Rink of Energy Technology Division for his assistance in performing SEM/EDX analyses of coupon specimens for this work. Valuable assistance has also been given by V. P. Kothari, N. T. Holcombe, and K. Das, Program Managers for this project at the U.S. DOE/Morgantown Energy Technology Center.

\subsection{REFERENCES}

1. H. S. Spacil, and K. L. Luthra, "Volatilization/Condensation of Alkali Salts in a Pressurized Fluidized Bed Coal Combustor/Gas Turbine Combined Cycle," J. Electrochem. Soc. $129,2119-2126$ (1982).

2. L. A. Scandrett, and R. Clift, "The Thermodynamics of Alkali Removal from Coal-Derived Gases," J. Inst. Energy 57, 391-397 (1984).

3. W. Mojtahedi, and R. Backman, "The Fate of Sodium and Potassium in the Pressurized Fluidized-Bed Combustion and Gasification of Peat," J. Inst. Energy 62, 189-196 (1989).

4. W. T. Reid, Ed., External Corrosion Deposits-Boilers and Gas Turbines, 1st Ed., American Elsvier Publishing Co., New York (1971).

5. H. H. Lunt, "Hot Corrosion in Gas Turbines," ASME Paper No. 77-WA/Fu-3 (1977).

6. S. H. D. Lee, and I. Johnson, "Removal of Gaseous Alkali Metal Compounds from Hot Flue Gas by Particulate Sorbents," J. Eng. Power, ASME Trans. 102, 397-402 (1980).

7. S. H. D. Lee, and K. M. Myles, "Alkali Measurement in PFBC and its Control by Granular Bed of Activated Bauxitre," Proc. Int. Conf. on Fluidized-Bed Combustion, Boston, MA, May 3-7, 1987, Vol. II, pp. 793-801 (1987).

8. D. M. Bachovchin, M. A. Alvin, E. A. Dezubay, and P. R. Mulik, A Study of High Temperature Removal of Alkali in a Pressurized Gasification System, Report No. DOE-MC-20050-2226, Westinghouse Res. Dev. Center, Pittsburgh, PA (1986).

9. M. Uberoi, W. A. Punjak, and F. Shadman, "The Kinetics and Mechanism of Alkali Removal from Flue Gases by Solid Sorbents," Prog. Energy Combust. Sci. 16, 205-211 (1990).

10. K. Natesan, "Role of FBC Deposits in the Corrosion of Heat Exchanger Materials," High Temperature Technology $\underline{4}, 193$ (1986).

11. K. Natesan, Laboratory Studies on Corrosion of Material for Fluidized Bed Combustion Applications, Argonne National Laboratory Report, ANL/FE-90/1 (Oct. 1990). 
12. J. Stringer, "Hot Corrosion of High Temperature Alloys," Ann. Rev. Mater. Sci. ㄱ, 477 (1977).

13. J. A. Goebel, F. S. Pettit, and G. W. Goward, "Mechanisms for the Hot Corrosion of Nickel-Base Alloys," Met. Trans. $\underline{4}, 261$ (1973).

14. K. L. Luthra, and D. A. Shores, "Mechanism of $\mathrm{Na}_{2} \mathrm{SO}_{4}$ Induced Corrosion at $600-900^{\circ} \mathrm{C}$," J. Electrochem. Soc. 127, 2202 (1980).

15. S. Kihara, and K. Nakagawa, Laboratory Coal Ash Corrosion Tests, Electric Power Research Institute Report, 77 EPRI GS-6449 (July 1989).

16. An Investigation of Hot Corrosion and Erosion Occurring in a Fluid Bed Combustion--Gas Turbine Cycle Using Coal as Fuel, U.S. Energy Research and Development Administration, FE/1536-2 (May, 1977).

17. C. C. Hsu, I. Johnson, and M. Blander, Chemical Activities of Alkali Sulfates in Hot Corrosion, Argonne National Laboratory Report, ANL-77-84 (1978).

18. M. A. Alvin, E. P. O'Neill, and D. L. Keairns, "Thermodynamic Projections of Trace Element Release in Fluidized-Bed Combustion Systems," Proc. 5th Int. Conf. on Fluidized Bed Combustion, December 12-14, 1977, Washington, DC, Vol. II, pp. 526-541 (1978).

19. P. R. Mulik, M. A. Alvin, and D. M. Bachovchin, Simultaneous High-Temperature Removal of Alkali and Particulates in a Pressurized Gasification System, Final Technical Progress Report for April 1981 to July 1983, Westinghouse Electric Corporation, DOE/MC/16372-1548 (DE84005777), pp. 3-39 (September 1983).

20. S. H. D. Lee, R. F. Henry, S. D. Smith, W. I. Wilson, and K. M. Myles, Alkali Metal Vapor Removal from Pressurized Fluidized-Bed Combustor Flue Gas, Annual Report for October 1984-September 1985, Argonne National Laboratory Report, ANL/FE-86-7 (Nov. 1986).

21. S. H. D. Lee, and E. L. Carls, Measurement of Alkali Metal Vapors and Their Removal from a Pressurized Fluidized-Bed Combustor Process Stream, Annual Report for October 1986-September 1987, Argonne National Laboratory Report, ANL/FE-88-4 (March 1989).

22. R. L. McCarron, A. M. Beltran, H. S. Spacil, and K. L. Luthra, "Turbine Máterials Corrosion in the Coal-Fired Combined Cycle," Proc. 5th Int. Conf. on Fluidized-Bed Combustion, Washington, DC, December 12-14, 1977, Vol. III, pp. 714-736 (1977).

23. Pressurized Fluidized-Bed Combustion, R\&D Report No. 85, Interim No. 1, prepared by National Research Development Corporation, London, England, for Office of Coal 
Research, Department of Interior, Washington, DC 20240. Contract No. 14-32-0001-1511 (1975).

24. Energy Conversion From Coal Utilizing CPU-400 Technology, Final Report, Vol. I., FE/1536-1, Combustion Power Co., Inc. (March 1977).

25. A. G. Roberts, S. N. Barber, R. N. Phillips, K. K. Pillai, P. Raven, and P. Wood, Fluidized Bed Combustion--1000 Hour Test Program, Vol. III--Combustion Emission and Hot Gas Cleanup, NCB/Coal Utilization Research Laboratory, Report No. DOE/EF/10423-1103 (September 1981).

26. A. G. Roberts, K. K. Pillai, and P. Raven, Pressurized Fluidized Bed Combustion--Part Load Behavior, Vol I--Summary Report, NCB/Coal Utilization Research Laboratory, Report No. DOE/MC/14129-171 (or FE-14129-6) (September 1981).

27. Fluidized Bed Combustor-Initial Results Obtained in a 1 Ft by 1 Ft Fluidized-Bed Combustor Operating at Pressures up to $20 \mathrm{Atm}$, NCB/Coal Utilization Research Laboratory, Report No. DOE/MC/14129-1309 (September 1982).

28. V. Zakkay, J. D. McClung, P. Radhakrishnan, S. Panunzio, K. Sellakumar, A. Ganesh, "Gas and Alkali Emission from Pressurized Fluidized-Bed Combustion of Lignite," Proc. of 8th Int. Conf. on Fluidized-Bed Combustion, Vol. III, pp. 1186-1196 (July 1985).

29. W. J. Haas, Jr., and D. E. Eckels, Real Time Monitoring of Sodium and Potassium Concentrations in Flue Gas Produced During July and August 1987 Coal Combustion/Hot Gas Cleanup Studies at the Grimethorpe (England) PFBC Establishment, Ames Laboratory Report No. IS-4956 (July 1988).

30. S. H. D. Lee, and E. L. Carls, "Measurement of Sodium and Potassium Vapours in Pressurized Fluidized-Bed Combustion of Beulah Lignite," J. Inst. Energy $\underline{63}$, 203-210 (1990).

31. S. H. D. Lee, F. G. Teats, W. M. Swift, and D. D. Banerjee, "Alkali-Vapor Emission from PFBC of Illinois Coals," Combust. Sci. and Tech. 6ㅜ 327-336 (1992).

32. W. J. Haas, Jr., D. E. Eckels, R. N. Kniseley, and V. A. Fassel, "Development of Alkali and Trace Heavy Metal Monitors," Proc. of DOE Contractors' Meeting on High Temperature, High Pressure Particulate and Alkali Control in Coal Combustion Process Streams, February 3-5, 1981, Morgantown, WV, pp. 599-620 (1981).

33. W. J. Haas, Jr., D. E. Eckels, S. H. D. Lee, and R. F. Henry, "Recent Developments and Observations Pertinent to Real-Time Monitoring of Alkali Concentrations in Hot Gas Streams from Fluidized-Bed Combustion of Coal," Proc. DOE Fifth Annual Contractors' Meeting on Contaminant Control in Hot Coal-Derived Gas Streams, May 7-9, 1985, Morgantown, WV, pp. 493-512 (January 1986). 
Distribution for ANL-FE-95-01

Internal:

J. E. Harmon

K. M. Myles

W. J. Shack

T. F. Kassner

K. Natesan (5)

W. M. Swift

J. J. Laidler

R. B. Poeppel

S. H. D. Lee (10)

D. K. Schmalzer

R. W. Weeks

TIS Files

S. A. Miller

External:

DOE-OSTI, for distribution per UC-103 (40)

ANL-E Library (2)

ANL-W Library

Manager, Chicago Operations Office, DOE

D. L. Bray, DOE-CH

Chemical Technology Division Review Committee Members:

E. R. Beaver, Monsanto Company, St. Louis, MO

D. L. Douglas, Consultant, Bloomington, $\mathrm{MN}$

R. K. Genung, Oak Ridge National Laboratory, Oak Ridge, TN

J. G. Kay, Drexel University, Philadelphia, PA

G. R. St. Pierre, Ohio State University, Columbus, $\mathrm{OH}$

J. Stringer, Electric Power Research Institute, Palo Alto, CA

J. B. Wagner, Arizona State University, Tempe, AZ

R. C. Bedick, USDOE, Morgantown Energy Technology Center, Morgantown, WV

D. J. Beecy, USDOE, Office of Fossil Energy, Germantown, MD

H. Birnbaum, University of Illinois, Urbana, IL

D. Bonk, USDOE, Morgantown Energy Technology Center, Morgantown, WV

R. C. Buchanan, University of Cincinnati, Cincinnati, $\mathrm{OH}$

J. P. Carr, USDOE, Office of Fossil Energy, Germantown, MD

D. C. Cicero, USDOE, Morgantown Energy Technology Center, Morgantown, WV

K. Das, USDOE, Morgantown Energy Technology Center, Morgantown, WV

M. S. Dresselhaus, Massachusetts Institute of Technology, Cambridge, MA

D. E. Eckels, Ames Laboratory, Iowa State University, Ames, IA

M. R. Ghate, USDOE, Morgantown Energy Technology Center, Morgantown, WV

N. Holcombe, USDOE, Morgantown Energy Technology Center, Morgantown, WV

Illinois Institute of Natural Resources, Champaign, IL

B. G. Jones, University of Illinois, Urbana, IL

R. R. Judkins, Oak Ridge National Laboratory, Oak Ridge, TN

V. P. Kothari, USDOE, Morgantown Energy Technology Center, Morgantown, WV

C.-Y. Li, Cornell University, Ithaca, NY

S.-N. Liu, Freemont, CA

K. E. Markel, USDOE, Morgantown Energy Technology Center, Morgantown, WV

M. W. Pitt, USDOE, Office of Fossil Energy, Germantown, MD 
J. Shang, USDOE, Office of Fossil Energy, Washington, DC

R. E. Smith, Altran Corporation, Huntersville, NC

M. Williams, USDOE, Morgantown Energy Technology Center, Morgantown, WV

J. F. Zievers, Industrial Filter \& Pump Manufacturing Co., Cicero, $\mathbb{L}$ 